Sādhanā Vol. 36, Part 2, April 2011, pp. 223-249. (C) Indian Academy of Sciences

\title{
In-plane anisotropy in tensile deformation and its influence on the drawability of Nimonic c-263 alloy sheets
}

\author{
K ANKAMMA $^{1}$, D V V SATYANARAYANA ${ }^{2}$, \\ G CHANDRAMOHAN REDDY ${ }^{1}$, M KOMARAIAH $^{3}$ and \\ N ESWARA PRASAD ${ }^{4, *}$
${ }^{1}$ Mechanical Engineering Department, Mahatma Gandhi Institute of Technology, Hyderabad 500 075, India
${ }^{2}$ Defence Metallurgical Research Laboratory, DRDO, PO Kanchanbagh, Hyderabad 500 058, India
${ }^{3}$ Malla Reddy College of Engineering and Technology, Hakimpet Post, Secunderabad 500 014, India
${ }^{4}$ Regional Centre for Military Airworthiness (Materials), CEMILAC, DRDO, PO
Kanchanbagh, Hyderabad 500 058, India
e-mail: nep@cemilac.drdo.in

MS received 4 June 2010; accepted 18 February 2011

\begin{abstract}
An effort has been made to comprehensively evaluate and rationalize the in-plane anisotropy in tensile properties and the effect of aging on the nature of deformation (strain hardening behaviour) and formability characteristics, especially the limit drawing ratio and forming limit diagram. Despite weak crystallographic texture and excellent ductility and high work hardening exponents, the alloy sheets of C-263 exhibit significant extent of in-plane anisotropy in its tensile properties and yield loci. The absolute magnitudes of yield stress and the exact nature of anisotropy that can be predicted from the tensile part of the yield locus need to be employed with caution. This is because when the magnitudes of the yield stresses, obtained from yield locus are more than 5 times higher as compared to the yield and ultimate tensile strength values and the nature and degree of in-plane anisotropy under tensile loading matches with that of only the compressive yield stresses of yield locus. The alloy sheet, due to weak crystallographic texture and relatively high strengths, is found to be far more suitable for structural applications, rather than for deep drawing applications, which was reflected in low limit drawing ratio values (1.34 for CR+ST and 1.23 for peak aged conditions). Further, the study conducted reveals that the safer forming limits in strain space is higher for $\mathrm{CR}+\mathrm{ST}$ condition; while, the safer forming limits in stress space
\end{abstract}

*For correspondence 
are higher for peak aged $(\mathrm{CR}+\mathrm{ST}+1073 \mathrm{~K} / 8 \mathrm{~h})$ condition. Finally, detailed studies are outlined to arrive at suitable microstructural and textural characteristics that provide significantly enhanced drawability in the Nimonic C-263 alloy sheets.

Keywords. Nimonic C-263 alloy sheets; microstructure; texture; tensile deformation; in-plane anisotropy; yield loci; work hardening; deep drawability.

\section{Introduction}

The yield behaviour and the characteristics that influence the yield behaviour in several structural materials have been the subjects of a number of scientific studies for sheet metal applications. Recent studies have also attempted to correlate the microstructure, texture, in-plane anisotropy in yield stress and work hardening exponent to the deep drawability. In a set of comprehensive studies conducted on a variety of materials, including face centered cubic structured $\mathrm{Al}, \mathrm{Al}-\mathrm{Cu}$ and Al-Li sheet materials, Barlat and co-workers (Barlat \& Liu 1998; Cazacu \& Barlat 2003; Barlat et al 1991a, b; Barlat \& Chung 1993) have not only described the procedures and methodologies to study the influence of plastic deformation, texture and precipitation behaviour on the anisotropy and/or yield loci, but also strongly proposed and more or less established the close relations between nature of yielding, its anisotropy on the yield loci. Further, these authors have modelled the kinematic hardening effects of $\theta^{\prime}$ precipitation on the yield anisotropy in Al-Cu alloys (Barlat \& Liu 1998). In a different set of studies, Banabic and co-workers (Banabic \& Dannenmann 2001; Banabic et al 2004) have described the methodologies for the determination of anisotropic yield behaviour and its influence on limit strains in sheet metals. Several other authors (Kuwabara et al 2002; Hu 2003; Mattiasson \& Sigvant 2008) too have recently reported on the simulation of yield criteria and anisotropy in more anisotropic materials, such as steels for industrial sheet metal forming. While the first set of studies are of direct relevance to the present work (which also will be the subject(s) of further studies) and the later two sets of studies are very important in determining the sheet metal forming in general and drawability in particular. However, such studies required to be conducted in case of the Nimonic C-263 alloy as this particular alloy has been the prime candidate material for ultra-thin sheet applications for the honeycomb structures of thermal protection systems (TPSs).

The Nimonic C-263 alloy, whose formability (drawability) is studied in the present investigation, is a wrought nickel base superalloy and derives its strength from precipitation of fine, coherent $\gamma^{\prime}\left(\mathrm{Ni}_{3}(\mathrm{Al}, \mathrm{Ti})\right)$ within fcc $\gamma$ matrix. The alloy has excellent ambient and elevated temperature deformability with good welding characteristics. Nimonic C-263 is widely used as cold rolled sheet product for a number of high temperature applications such as aircraft turbine and land-based-turbine engine components, due to its high creep strength and superior oxidation resistance. These applications include low-temperature combustors, transition liners and ring components. However some of the recent applications of Nimonic C-263 alloy sheet, especially the ultra thin $(<450 \mu \mathrm{m}$ thickness) sheets for TPSs, need specific studies to evaluate in detail the factors that influence the cold rolling and drawability. Aging and in-plane anisotropy are the two most critical areas, which provide the scientific basis to this end. In the past, a few attempts have been made to study the deformation behaviour of this Ni-based superalloy for sheet metal applications. However, these studies were limited to different commercial grades such as cold rolled sheets of thicknesses up to $2 \mathrm{~mm}$. None of these studies have addressed the influence of microstructure and texture for ultra-thin sheet applications. Hence, a comprehensive study has 
been undertaken to evaluate the ambient temperature deformation characteristics as a function of degree of cold rolling and aging. The resultant in-plane anisotropy and its influence on the formability (drawability) characteristics are studied using the explicit dynamic analysis code LSDYNA and the results obtained are discussed in the present paper.

\section{Experimental details}

The Nimonic C-263 alloy sheets used in the present investigation were procured from Misra Dhatu Nigam (MIDHANI), Hyderabad, India. The nominal composition of the alloy sheet in wt.\%, is (0.045-0.053)C, (19.01-19.36)Co, (19.75-19.90)Cr, (5.86-6.01)Mo, (0.41-0.50)Al, (0.04-0.05)Si, (2.04-2.10)Ti, (0.42-0.43)Mn, (0.002-0.0043)B, (0.005)P and the balance is nickel. The as-received material was in the form of cold rolled and solution treated sheets of thicknesses 1.0 and $0.5 \mathrm{~mm}$. The cold rolled sheets were solution treated at $1423 \mathrm{~K}$ for 5-15 min., followed by air cooling. The sheet samples are further aged at $1073 \mathrm{~K}$ for 1,8 and $20 \mathrm{~h}$. Tensile tests at room temperature were conducted on INSTRON 5500R universal testing machine at a cross-head speed of $1 \mathrm{~mm}$ per minute (corresponding to an initial stain rate of $\sim 5 \times 10^{-4} \mathrm{~s}^{-1}$ ) using flat specimens of gauge length $25 \mathrm{~mm}$ and width $6 \mathrm{~mm}$. The axial strain was monitored with the help of an axial extensometer of $25 \mathrm{~mm}$ gauge length.

The alloy sheet in the as-received, i.e., cold rolled and solution treated $(\mathrm{CR}+\mathrm{ST})$ condition was further subjected to aging treatment at $1073 \mathrm{~K}$ in a vacuum furnace for different durations. Specimens for microstructure (both optical and transmission electron microscopy), and texture evaluation, Vicker's macro hardness and tensile property evaluation were withdrawn from the vacuum heat treatment furnace after appropriate duration of aging treatment. Based on the aging curve (variation of Vickers macro hardness with aging time), as shown in figure 1, tensile properties were evaluated on specimens from 0.5 to $1.0 \mathrm{~mm}$ thick alloy sheets that were aged at this

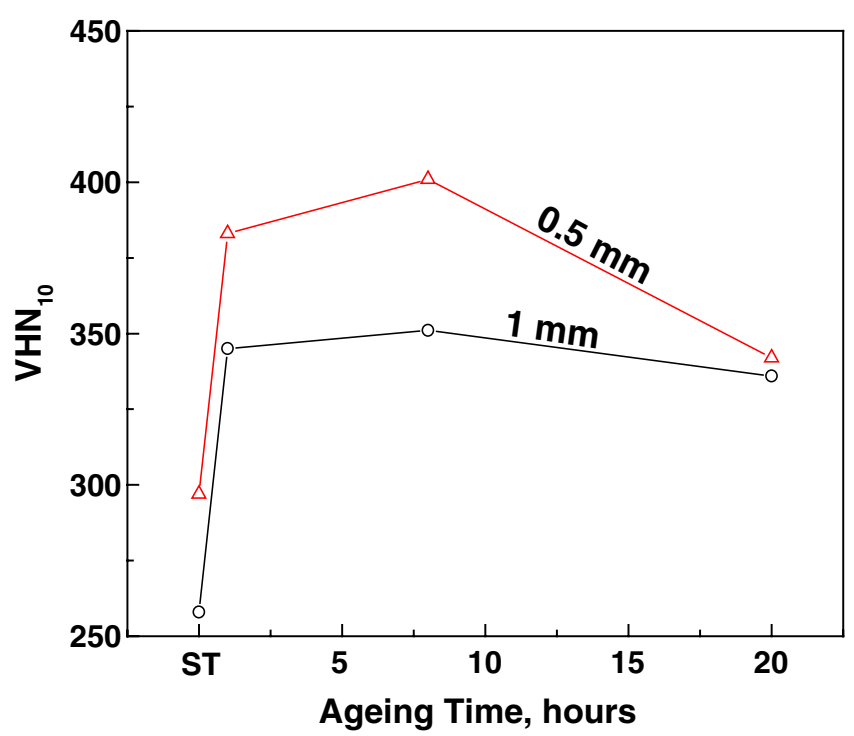

Figure 1. Vickers macro hardness values of Nimonic C-263 alloy as a function of aging time at $1073 \mathrm{~K}$ for $1.0 \mathrm{~mm}$ and $0.5 \mathrm{~mm}$ thickness sheets. 
Table 1. Vickers macro hardness and $0.2 \%$ yield stress values of Nimonic C-263 alloy sheets in CR+ST and in different aged conditions of $1.0 \mathrm{~mm}$ and $0.5 \mathrm{~mm}$ thickness.

\begin{tabular}{lccccr}
\hline Aging condition & \multicolumn{3}{c}{$\mathrm{VHN}_{10}$} & & \multicolumn{2}{c}{$\begin{array}{c}0.2 \% \text { Yield stress (MPa) } \\
\text { at } \epsilon=10^{-4} \mathrm{~s}^{-1}\end{array}$} \\
\cline { 2 - 3 } & $1.0 \mathrm{~mm}$ & $0.5 \mathrm{~mm}$ & & $1.0 \mathrm{~mm}$ & $0.5 \mathrm{~mm}$ \\
\hline $\mathrm{CR}+\mathrm{ST}$ & 258 & 297 & & 556 & 704 \\
$\mathrm{CR}+\mathrm{ST}+1073 \mathrm{~K} / 1 \mathrm{~h}$ [under age] & 345 & 383 & & 792 & 883 \\
$\mathrm{CR}+\mathrm{ST}+1073 \mathrm{~K} / 8 \mathrm{~h}$ [peak age] & 351 & 401 & & 845 & 999 \\
$\mathrm{CR}+\mathrm{ST}+1073 \mathrm{~K} / 20$ h [over age] & 336 & 342 & & 752 & 816 \\
\hline
\end{tabular}

temperature for select durations of 1, 8 and 20 hours which correspond to under-aged, peak-aged and overaged conditions, respectively (table 1).

\section{Results}

\subsection{Initial microstructure}

Figure 2 shows optical micrograph of the alloy sheet in the as-received cold rolled and solution treated condition. Microstructure was found to be quite uniform and it principally consists of partially recrystallized, equi-axed grains in sheet surface and unrecrystallised grains in sheet thickness direction with high density of annealing twins. The average grain size is approximately $30 \mu \mathrm{m}$ in the surface direction.

Transmission electron micrographs, given in figures 3 and 4 show the finer microstructural details of the alloy sheet of $1.0 \mathrm{~mm}$ thickness in the as-received, i.e., CR+ST as well as peak aged condition (the features are similar to $0.5 \mathrm{~mm}$ thick sheet). The TEM examination reveals that the matrix of the present Nimonic sheet does not contain any detectable levels of strengthening precipitates in the $\mathrm{CR}+\mathrm{ST}$ condition. However, the alloy sheet in the $\mathrm{CR}+\mathrm{ST}$ condition was found to contain significant amounts of MC type carbides (enriched with Ti) within the grains (figure 3a). On the other hand, fine $\mathrm{M}_{23} \mathrm{C}_{6}$ (enriched with $\mathrm{Cr}$ ) type of carbides were present

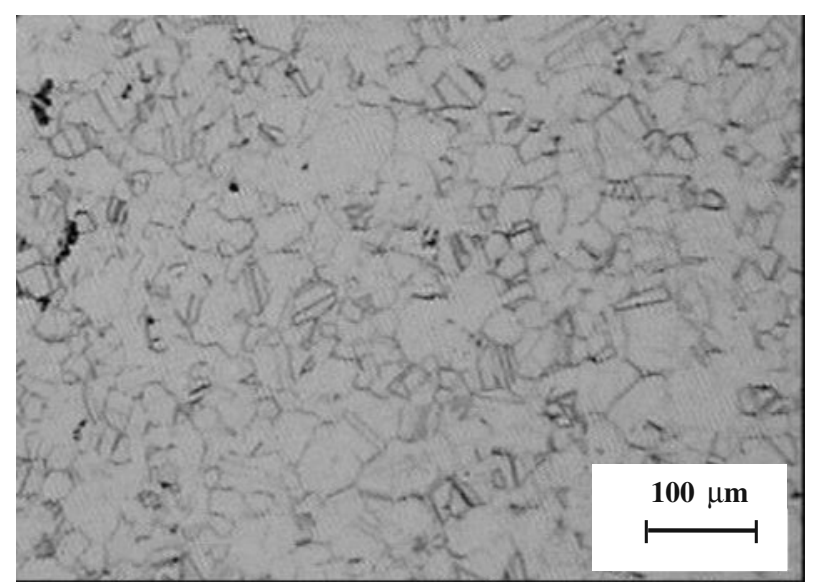

Figure 2. Optical micrograph of Nimonic C-263 alloy sheet in the as-received cold rolled and solution treated $(\mathrm{CR}+\mathrm{ST})$ condition. 


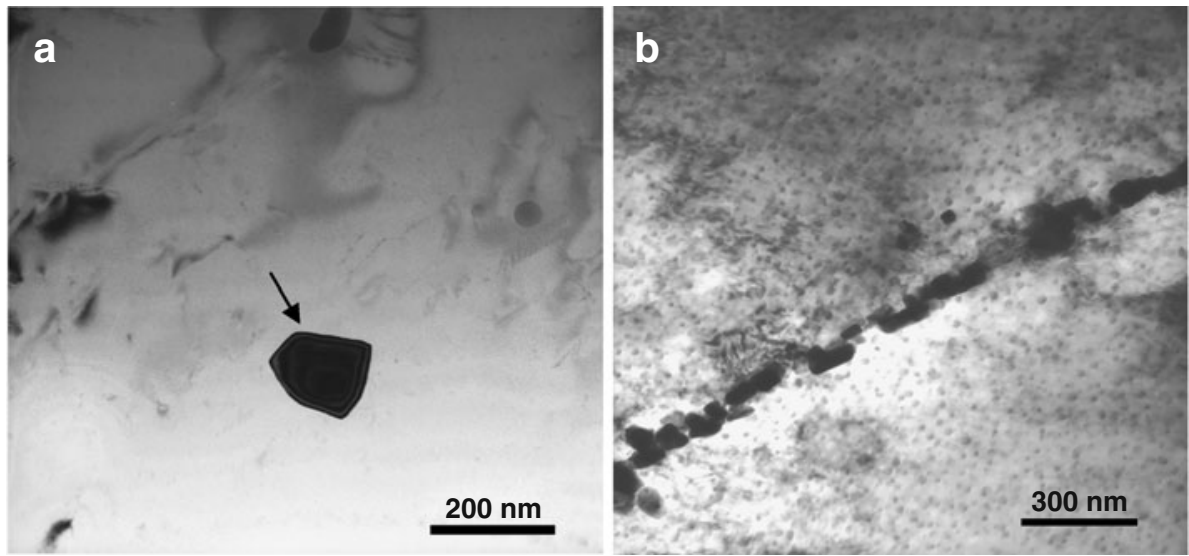

Figure 3. TEM bright field images showing the (a) MC type carbide particle, (b) $M_{23} C_{6}$ type carbides at the twin boundary.

along the grain and twin boundaries (figure $3 \mathrm{~b}$ ) in the aged condition. Further, the alloy sheet in the aged condition was also found to contain large volume fraction of uniformly distributed $\gamma^{\prime}\left(\mathrm{Ni}_{3}(\mathrm{Al}, \mathrm{Ti})\right)$ precipitates (figure 4), the main strengthening phase in this alloy.

\subsection{XRD and texture}

Specimens from as-received, cold rolled and solution treated alloy sheets of $1.0 \mathrm{~mm}$ and $0.5 \mathrm{~mm}$ thickness were subjected to X-ray diffraction studies using normal Bragg scan. The XRD profiles were recorded from the ND planes of the rolled specimens. The XRD patterns of cold rolled and solution treated specimens of $1.0 \mathrm{~mm}$ thickness, as shown in figure 5, (the features are similar to $0.5 \mathrm{~mm}$ thick sheet) exhibit the change in intensity from that of powder pattern indicating the presence of crystallographic texture. The XRD patterns of both the specimens exhibit highest intensity for (220) plane. However, the texture of the specimen shown
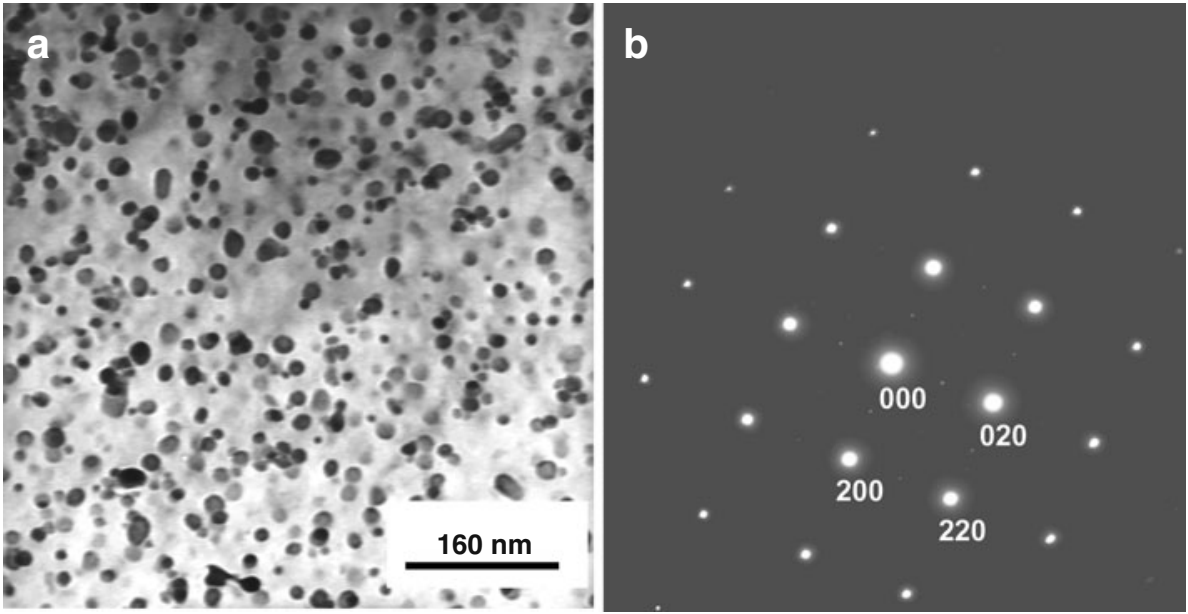

Figure 4. (a) TEM bright field images showing $\gamma^{\prime}$ precipitates in $<100>$ matrix orientation after aging at $1073 \mathrm{~K} / 8 \mathrm{~h}$. (b) Selected area electron diffraction pattern. 


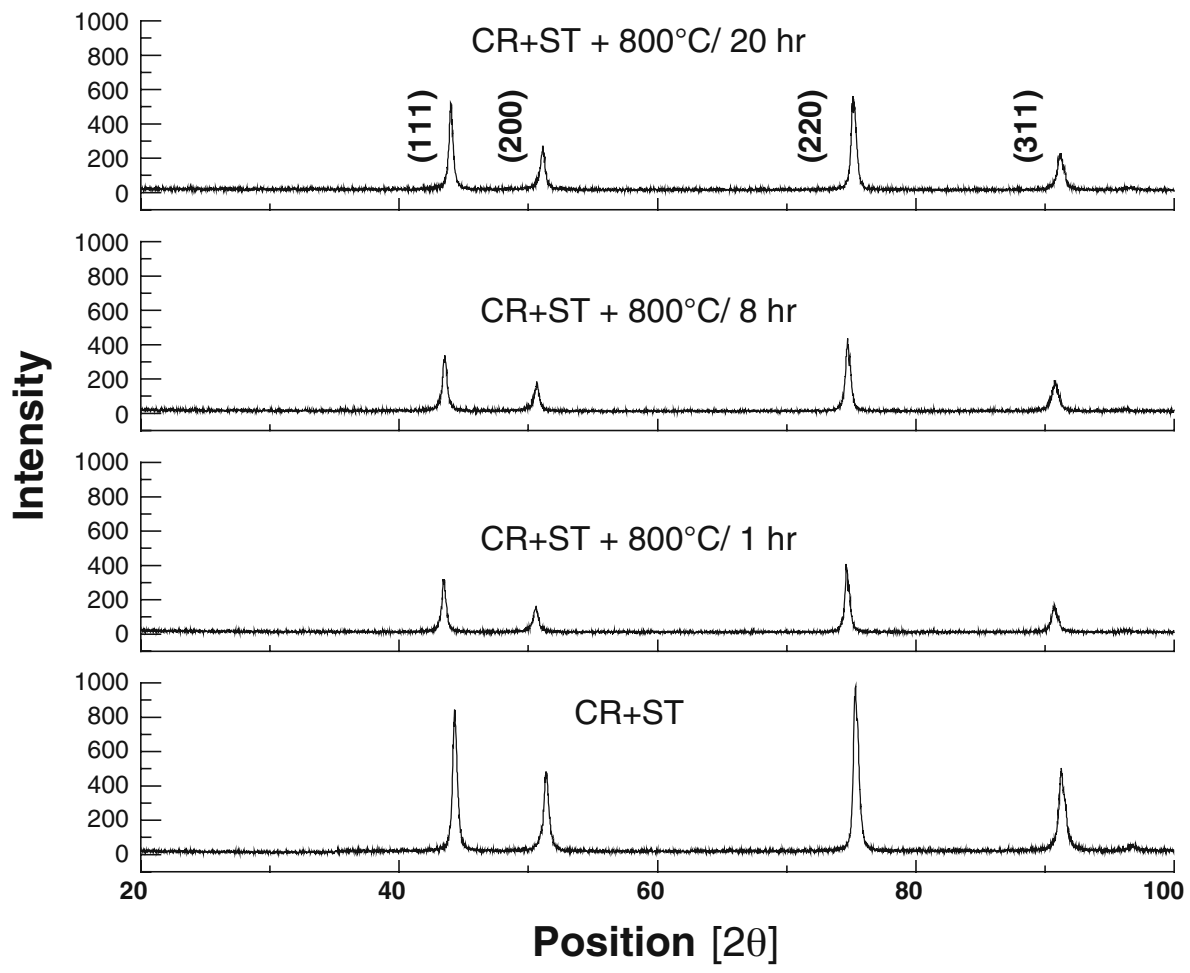

Figure 5. XRD pattern of cold rolled Nimonic C-263 alloy sheet of $1.0 \mathrm{~mm}$ thickness in solution treated and in different aged conditions.

in figure 6 displays weak intensity texture. The overall intensity of $1.0 \mathrm{~mm}$ thick specimen is nearly same as that of $0.5 \mathrm{~mm}$ thick specimen. The (111) and (200) pole figures of $1.0 \mathrm{~mm}$ specimen too reveal overall weak texture with several low intensity components (figure 6). The main texture components from the corresponding ODF are given in table 2. The intensities $(\mathrm{f}(\mathrm{g}))$

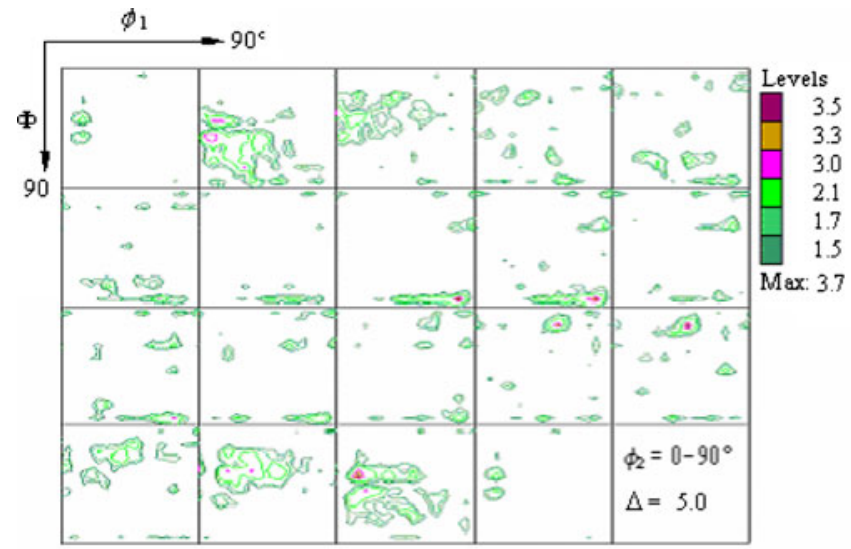

(a)

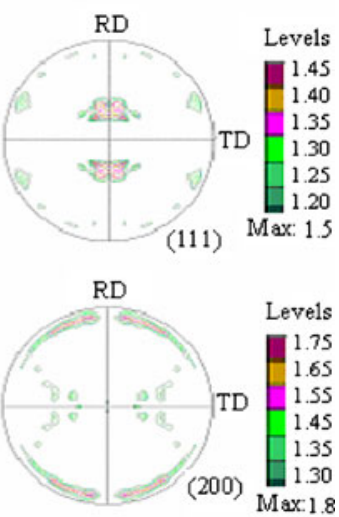

(b)

Figure 6. (a) $\varphi_{2}$ Section of the ODF plot. (b) Pole figures of (111) and (200), of the alloy of $1.0 \mathrm{~mm}$ thickness in the as-received $\mathrm{CR}+\mathrm{ST}$ condition. 
Table 2. Details of the texture components obtained in $1.0 \mathrm{~mm}$ and $0.5 \mathrm{~mm}$ thick specimens.

\begin{tabular}{lclcc}
\hline $1.0 \mathrm{~mm}$ thick specimen & & & $0.5 \mathrm{~mm}$ thick specimen & \\
\cline { 5 - 5 } Texture component & $\mathrm{f}(\mathrm{g}) \times$ random & & Texture component & $\mathrm{f}(\mathrm{g}) \times$ random \\
\hline$\{011\}<211>$ & 2.2 & & $\{518\}<911>$ & 3.2 \\
$\{1115\}<110>$ & 2.2 & & $\{132\}<643>$ & 2.4 \\
$\{111\}<110>$ & 2.0 & $\{011\}<211>$ & 1.6 \\
$\{112\}<021>$ & 2.2 & $\{012\}<100>$ & 1.2 \\
$\{223\}<110>$ & 2.3 & $\{112\}<201>$ & 2.5 \\
$\{012\}<100>$ & 2.4 & $\{441\}<110>$ & 1.7 \\
$\{011\}<122>$ & 2.3 & $\{111\}<213>$ & 1.9 \\
\hline
\end{tabular}

of the texture components are reported as 'times random'. It is to be noted that a few components such as $\{011\}<211>,\{001\}<110>$ which is nearly $5^{\circ}$ away from $\left\{\begin{array}{lll}1 & 1 & 15\end{array}\right\}<110>$ and $\{132\}<643>$ have been reported in recrystallized fcc metals and alloys (Humphreys \& Hatherly 1995). However, the presence of $\left\{\begin{array}{lll}1 & 1 & 15\end{array}\right\}<110>$ and other components which are not very far off from typical recrystallization texture components thus indicates that solution treatment after cold rolling has not produced stable end orientations.

The XRD patterns of solution treated and aged specimens are included in figure 5. The lattice parameters of matrix and $\gamma$ ' are so close that they can not be resolved by XRD technique. Therefore, the XRD peaks observed in the aged specimens correspond to both the matrix and $\gamma$ ' precipitates. It is noted that (220) peak of solution treated specimens exhibits highest intensity. The aging of the specimens initially decreases the intensity of (220) peak and further increases with increase in aging time. These observations can be attributed to the $\gamma$ ' precipitate coarsening and the accompanied progressive loss of coherency.

\subsection{Tensile properties}

The engineering stress-strain curves were obtained from the tensile testing of the alloy sheets of 1.0 and $0.5 \mathrm{~mm}$ thicknesses in the $\mathrm{CR}+\mathrm{ST}$ and peak aged conditions (typical set of curves are
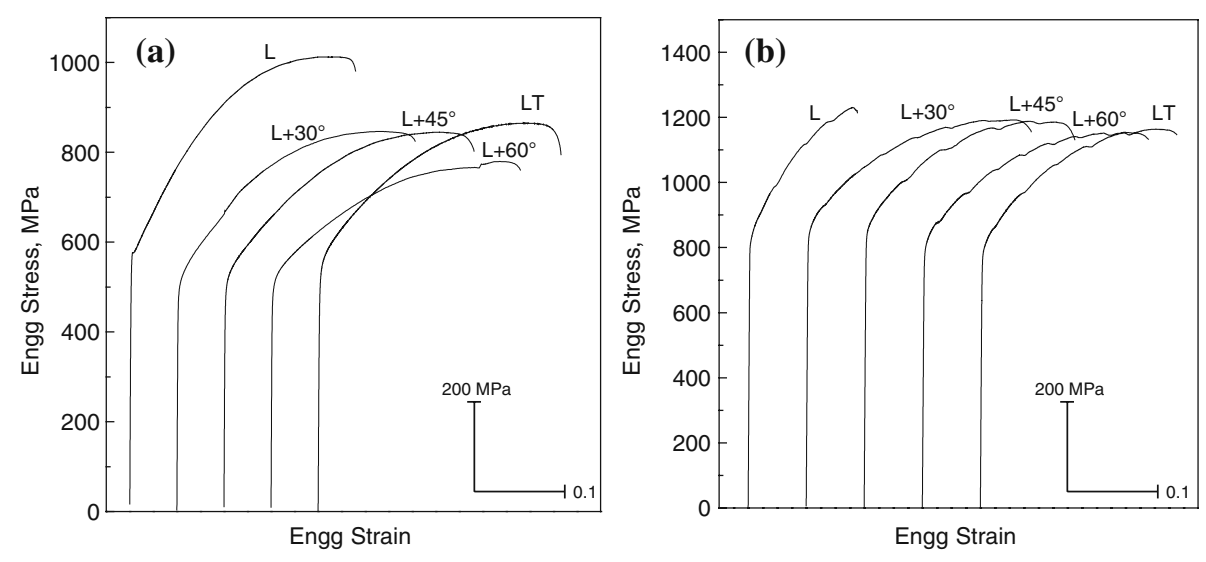

Figure 7. Engineering stress-engineering strain data of Nimonic C-263 alloy of $1.0 \mathrm{~mm}$ thickness in (a) $\mathrm{CR}+\mathrm{ST}$ condition and (b) peak aged $(\mathrm{CR}+\mathrm{ST}+1073 \mathrm{~K} / 8 \mathrm{~h}$ aged) condition. (All tests were conducted at room temperature in laboratory air atmosphere using an initial strain rate of $10^{-4} \mathrm{~s}^{-1}$ ). 
shown in figure 7). Both alloy sheets in the $\mathrm{CR}+\mathrm{ST}$ condition exhibit significantly lower strength and higher strains to fracture as compared to the peak aged condition. An interesting aspect in the observed tensile deformation has been the fact that, unlike the alloy sheet in CR+ST condition, the peak aged alloy sheets exhibited significant extent of serrated plastic flow. A detailed study is in progress to determine the specific reasons of this observation - the dynamic strain aging (DSA) due to interaction of solute atoms with dislocations or progressive shearing of $\gamma$ ' precipitates. Tensile properties of Nimonic C-263 alloy sheet of $1.0 \mathrm{~mm}$ thickness in the cold rolled and solution treated $(\mathrm{CR}+\mathrm{ST})$ and peak aged $(\mathrm{CR}+\mathrm{ST}+1073 \mathrm{~K} / 8 \mathrm{~h}$ aged $)$ conditions as a function of orientation with respect to the rolling direction have been determined and the results are graphically shown in figures 8 and 9 . The results are similar to $0.5 \mathrm{~mm}$ thick alloy sheet. As the orientation changes from 0 to $90^{\circ}$, the yield strength and ultimate tensile strength (UTS) decrease gradually. On the other hand, the ductility and the uniform strain increase from 0 to $60^{\circ}$ and then decrease from $60^{\circ}$ to $90^{\circ}$. The variation in the work hardening characteristics, in terms of the work hardening exponent (n) and the ratio of ultimate tensile to yield strength values, are included in figures 8 and 9 . The orientation dependence in the tensile properties of the $0.5 \mathrm{~mm}$ thickness sheet are similar to the $1.0 \mathrm{~mm}$ thickness sheet (see data in figures 8 and 9). The observed anisotropy in the present study can be understood in terms of the calculation of
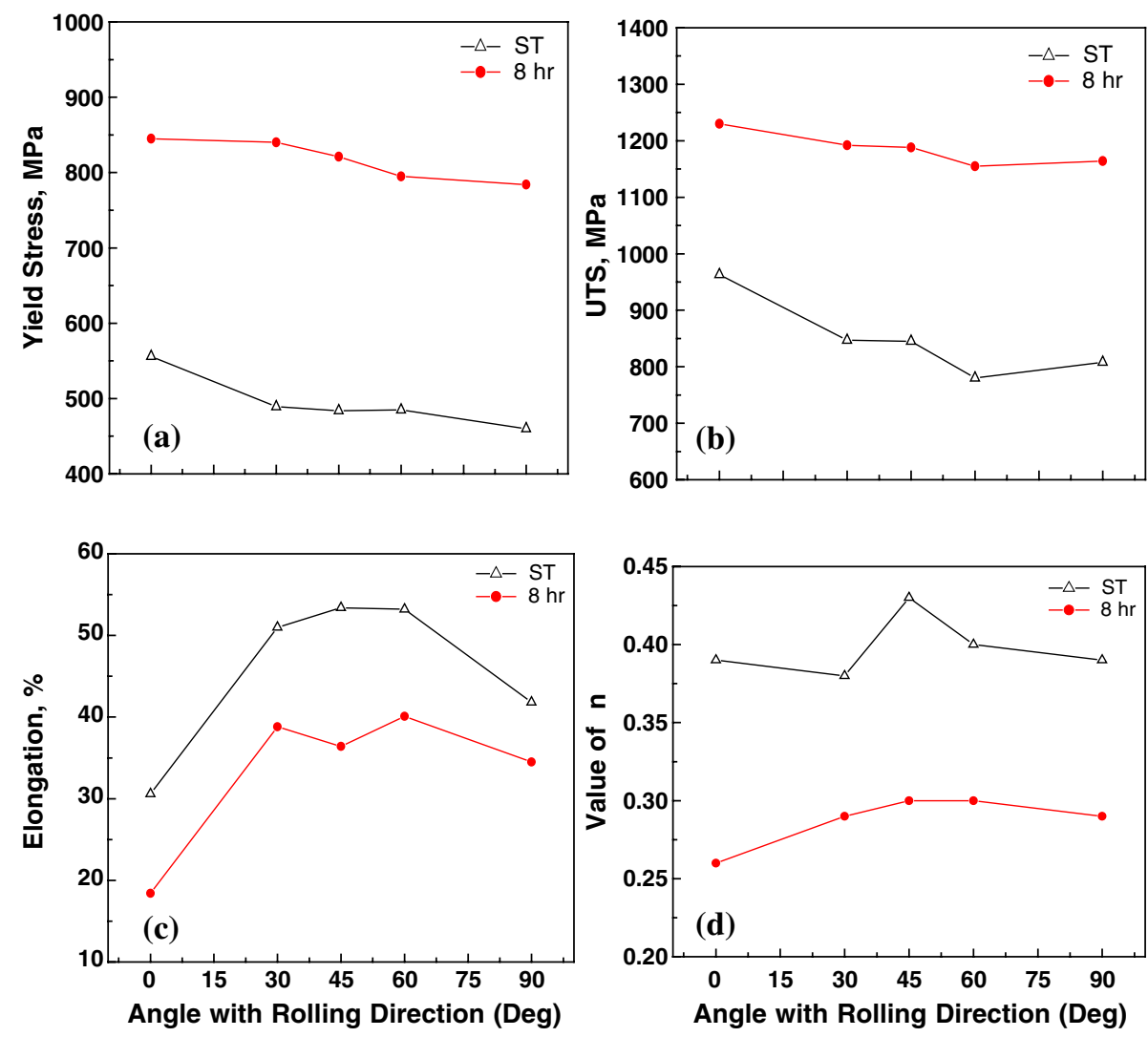

Figure 8. Anisotropy in tensile properties of Nimonic C-263 alloy sheet of $1.0 \mathrm{~mm}$ thickness in CR+ST and peak aged $(\mathrm{CR}+\mathrm{ST}+1073 \mathrm{~K} / 8 \mathrm{~h}$ aged) condition, showing the variation with respect to the rolling direction in (a) $0.2 \%$ Yield stress, (b) UTS, (c) elongation, and (d) work hardening exponent, n. 
(a)

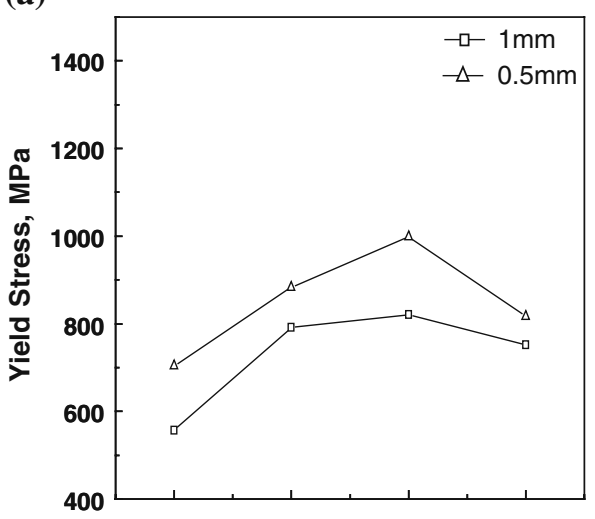

(c)

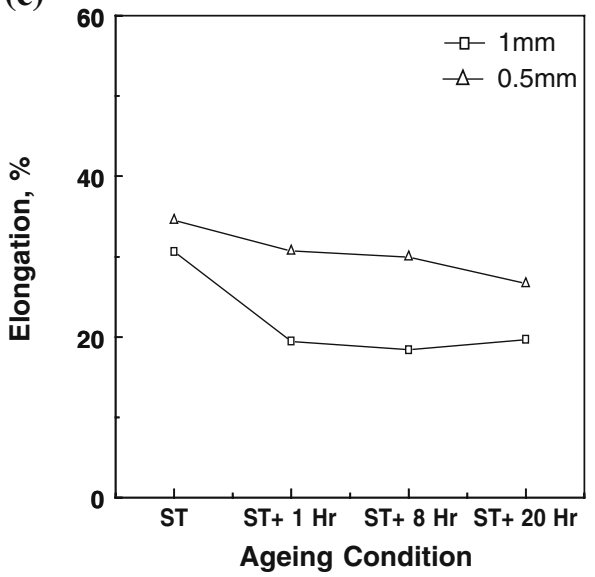

(b)

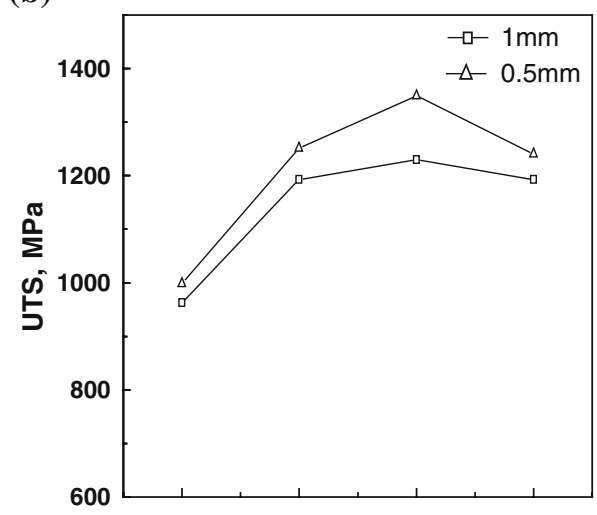

(d)

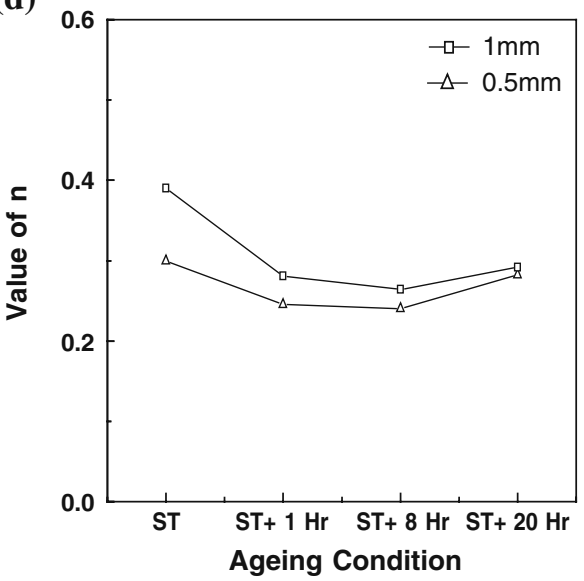

Figure 9. In-plane anisotropy in tensile properties (a) $0.2 \%$ yield stress, (b) UTS, (c) elongation and (d) work hardening exponent (n) of Nimonic C-263 alloy sheets of 1.0 and $0.5 \mathrm{~mm}$ thicknesses in CR+ST and in different aged conditions (all tests were conducted at room temperature in laboratory air atmosphere using a strain rate of $10^{-4} \mathrm{~s}^{-1}$ ).

Schmid factors, based on textural characterization, following the procedures suggested by Peters et al (1986) and Tempus et al (1991).

\section{Discussion}

\subsection{Yield loci}

The yield locus has been generated from the calculated yield stress values below and from the experimentally determined Knoop Hardness Number (KHN) values in the six orientations of $\mathrm{a}-\mathrm{f}$ as shown in figure 10 .

A material KHN flow surface is constructed from the six KHN values obtained from the indentations made along two directions of each of the three orthogonal planes of material's principal axes (along rolling, $\mathrm{x}$, designated as longitudinal, L; along transverse, $\mathrm{y}$, designated as long-transverse, LT; along thickness, z, called short-transverse or through-thickness, defined 
(a)

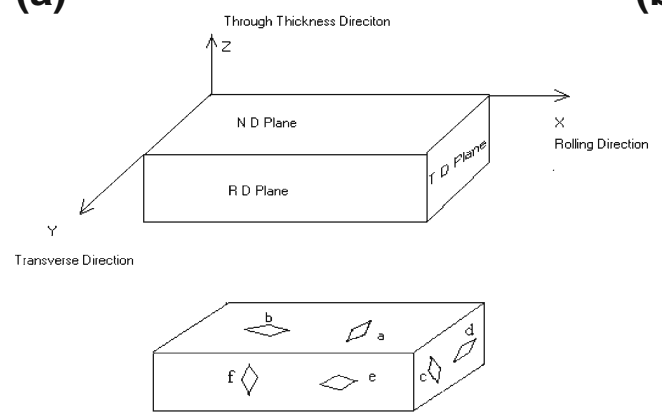

(b)

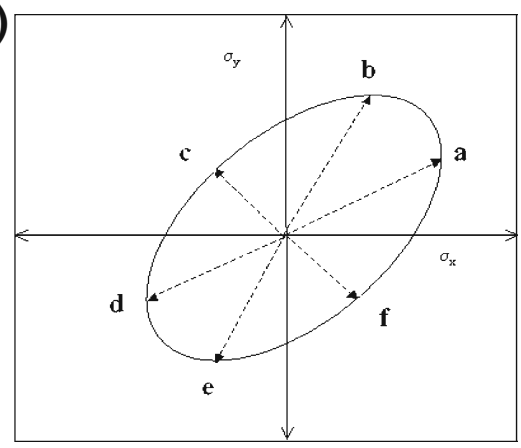

Figure 10. (a) A three-dimensional representation of ND, TD and RD planes of the rolled sheet and orientations of Knoop indentations used in the micro-hardness testing on three orthogonal planes. (b) Schematic showing the locations of points a-f, corresponding to the six directions on the yield locus.

in figure 10a. The six values (a to f) are graphically represented in figure 10b. The ratio 7 to 1 has been selected because it produces flow surfaces similar in shape with surfaces determined by standard method (Wheeler \& Ireland 1966). It is believed that this value originates in the usual ratio of major to minor diagonal in Knoop indentation, which is about 7:1. This has been favoured for two reasons: (i) the deformation under a Knoop indenter approaches plain strain when $d \varepsilon_{w} / d \varepsilon_{i}=\alpha$ and (ii) shape of the locus where plane strain represented is not overly sensitive either to the exact value of $d \varepsilon_{w} / d \varepsilon_{i}$ or to the degree of anisotropy, within a rather wide range of both variables. Hence, the values of $\alpha$ will be different for different orientations $(a-f)$ of figure $10 \mathrm{~b}$ and are given for orientations $(\mathrm{a}-\mathrm{f})$, as;

$$
\alpha_{a}=\sigma_{y} / \sigma_{x}=(2+\delta) /(2 \delta+1)
$$

and,

$$
\alpha_{b}=1 / \alpha_{a}, \alpha_{c}=(1-\delta) /(2+\delta), \alpha_{d}=(\delta-1) /(1+2 \delta), \alpha_{e}=1 / \alpha_{d}, \alpha_{f}=1 / \alpha_{c}
$$

$$
K H N \approx\left(\sigma_{x}^{2}-\sigma_{x} \sigma_{y}+\sigma_{y}^{2}\right)^{1 / 2}
$$

Or

$$
\sigma_{i} \approx K H N\left(1-\alpha_{i}+\alpha_{i}^{2}\right)^{-1 / 2},
$$

where $\sigma_{i}$ represents the stress in one of the orientation of a-f, which enables the construction of yield locus. A best fit ellipse drawn from all the six yield stresses of $\sigma_{\mathrm{a}}$ to $\sigma_{\mathrm{f}}$ provides the yield locus and the yield locus thus established for the present alloy in the two heat treat conditions are shown in figure 11 for $1.0 \mathrm{~mm}$ thickness sheet. From the yield locus plots, the intersection points on the $\mathrm{x}$ (longitudinal or rolling direction) and $\mathrm{y}$ (transverse direction) provide the $\sigma_{\mathrm{x}}$ and $\sigma_{\mathrm{y}}$ values, respectively for the tension and compression loading. These values are given in table 4, along with the experimentally determined yield and ultimate tensile strength values obtained from tensile testing. The best fit ellipse, generated from the present study, indicates the presence of significant extent of anisotropy, since the experimental points do not lie on the best fit ellipse (figure 11). This can be seen from the value of the sum of the average root mean square values between experimentally determined yield locus stress values corresponding to $(\mathrm{a}-\mathrm{f})$ and the best fit elliptical yield locus, which is designated as root mean square error 
(a)

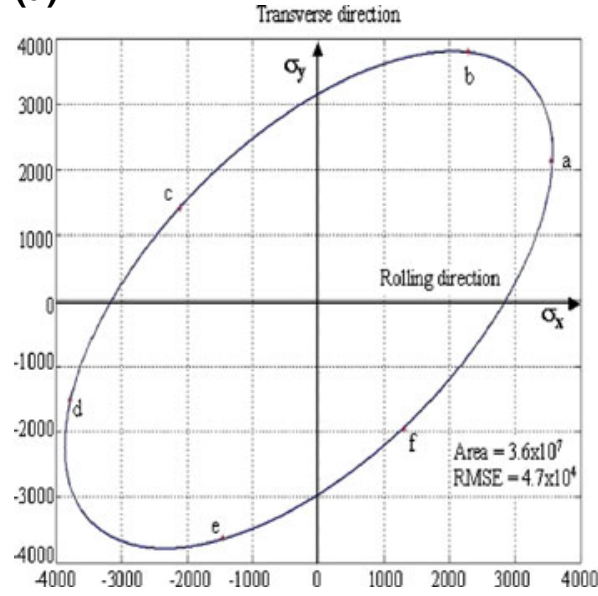

(b)

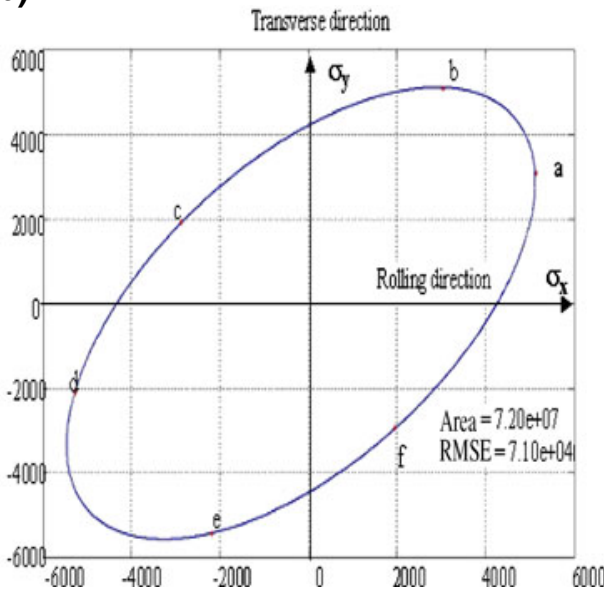

Figure 11. Yield locus anisotropy of the Nimonic C-263 alloy of $1.0 \mathrm{~mm}$ thickness in (a) CR+ST, (b) peak aged $(\mathrm{CR}+\mathrm{ST}+1073 \mathrm{~K} / 8 \mathrm{~h}$ aged) condition.

(RMSE) and the value of the RMSE determined is $0.0047 \times 10^{7}$ (see data in figure 11a), which value is found to be significantly higher for the aged condition $\left(7.2 \times 10^{7}\right.$; see data in figure 11b). The trends in yield locus behaviour are similar to $0.5 \mathrm{~mm}$ thick alloy sheet as well. The larger the value of RMSE, higher is the extent of anisotropy present in the material. The large difference in the values of $\sigma_{\mathrm{x}}$ and $\sigma_{\mathrm{y}}$ in tension and compression too indicate high degree of anisotropy. This observation is in agreement with the in-plane anisotropy, as reflected in tensile strengths - both yield and ultimate tensile strengths. The data in table 4 further show that the nature and magnitude of in-plane anisotropy in the tensile yield and ultimate strengths match with that of the compression flow stresses of the yield locus, but not with the tensile counterpart.

Table 3. Yield locus data of Nimonic C-263 alloy sheet of $1.0 \mathrm{~mm}$ thickness in (A) CR+ST and (B) peak aged $(\mathrm{CR}+\mathrm{ST}+1073 \mathrm{~K} / 8 \mathrm{~h}$ aged) condition in different orientations.

\begin{tabular}{|c|c|c|c|c|c|c|}
\hline \multirow[t]{2}{*}{ S.NO } & \multirow{2}{*}{$\begin{array}{l}\text { Indentation } \\
\text { orientation }\end{array}$} & \multirow{2}{*}{$\begin{array}{l}\alpha=\sigma_{y} / \sigma_{x} \\
\text { with } \delta=7\end{array}$} & \multirow[t]{2}{*}{$\sqrt{\left(1-\alpha+\alpha^{2}\right)}$} & \multirow{2}{*}{$\begin{array}{c}\text { KHN at } \\
100 \mathrm{~g} \mathrm{Load}\end{array}$} & \multicolumn{2}{|c|}{ Stress in $\mathrm{MPa}$} \\
\hline & & & & & $\sigma_{x}$ & $\sigma_{y}$ \\
\hline \multicolumn{7}{|c|}{ (A) $\mathrm{CR}+\mathrm{ST}$ condition } \\
\hline 1 & $\mathrm{a}$ & 0.6 & 0.872 & 315.47 & 3549.1 & 2129.8 \\
\hline 2 & $\mathrm{~b}$ & 1.67 & 1.454 & 338.31 & 2282.5 & 3805.0 \\
\hline 3 & $\mathrm{c}$ & 0.67 & 1.454 & 312.84 & -2110.7 & 1407.8 \\
\hline 4 & $\mathrm{~d}$ & 0.4 & 0.872 & 337.12 & -3792.5 & -1517.0 \\
\hline 5 & $\mathrm{e}$ & 2.5 & 2.18 & 322.87 & -1452.9 & -3632.2 \\
\hline 6 & $\mathrm{f}$ & 1.5 & 2.18 & 289.73 & 1303.8 & -1955.6 \\
\hline \multicolumn{7}{|c|}{ (B) Peak aged (CR+ST+1073 K/8 h aged) condition } \\
\hline 1 & $\mathrm{a}$ & 0.6 & 0.872 & 456.4 & 5134.5 & 3080.7 \\
\hline 2 & $\mathrm{~b}$ & 1.67 & 1.454 & 451.5 & 3046.2 & 5087.1 \\
\hline 3 & $\mathrm{c}$ & 0.67 & 1.454 & 426.1 & -2874.8 & 1926.1 \\
\hline 4 & $\mathrm{~d}$ & 0.4 & 0.872 & 467.8 & -5262.7 & -2105.0 \\
\hline 5 & $\mathrm{e}$ & 2.5 & 2.18 & 483.9 & -2177.5 & -5443.7 \\
\hline 6 & $\mathrm{f}$ & 1.5 & 2.18 & 435.1 & 1957.9 & -2936.8 \\
\hline
\end{tabular}


Table 4. Summary of the yield data of the Nimonic C-23 alloy sheet of 1.0 and $0.5 \mathrm{~mm}$ thicknesses in $\mathrm{CR}+\mathrm{ST}$ and in the peak aged (CR+ST+1073 K/8 h aged) conditions.

\begin{tabular}{|c|c|c|c|c|}
\hline \multirow[t]{3}{*}{ Description } & \multicolumn{4}{|c|}{ Value } \\
\hline & \multicolumn{2}{|c|}{$1.0 \mathrm{~mm}$} & \multicolumn{2}{|c|}{$0.5 \mathrm{~mm}$} \\
\hline & $\mathrm{CR}+\mathrm{ST}$ & Peak aged & $\mathrm{CR}+\mathrm{ST}$ & Peak aged \\
\hline \multicolumn{5}{|l|}{ Tensile yield strength, in MPa } \\
\hline L Direction & 556 & 845 & 704 & 999 \\
\hline LT Direction & 460 & 784 & 615 & 837 \\
\hline \multicolumn{5}{|l|}{ Ultimate tensile strength, in $\mathrm{MPa}$} \\
\hline L Direction & 963 & 1230 & 998 & 1349 \\
\hline LT Direction & 808 & 1164 & 909 & 1147 \\
\hline \multicolumn{5}{|l|}{ Yield stress from yield locus, in $\mathrm{MPa}$} \\
\hline L Direction - Tension & 2826.0 & 4292.7 & 3353.0 & 4400.0 \\
\hline L Direction - Compression & 3592.6 & 4341.5 & 3526.3 & 4881.3 \\
\hline \multicolumn{5}{|l|}{ Yield stress from yield locus, in $\mathrm{MPa}$} \\
\hline LT Direction - Tension $\left(\sigma_{x}\right)$ & 3179.5 & 4230.7 & 3411.7 & 4450.0 \\
\hline LT Direction - Compression $\left(\sigma_{y}\right)$ & 2948.7 & 4461.5 & 3842.1 & 4508.5 \\
\hline \multicolumn{5}{|c|}{ Anisotropy - Ratio of stress in L and LT directions w.r.t } \\
\hline Tensile yield stress & 1.21 & 1.08 & 1.14 & 1.20 \\
\hline Tensile UTS & 1.19 & 1.06 & 1.10 & 1.17 \\
\hline$\sigma_{x}$ of Yield locus & 0.88 & 1.01 & 0.98 & 0.99 \\
\hline$\sigma_{y}$ of Yield locus & 1.22 & 0.98 & 0.92 & 1.08 \\
\hline \multicolumn{5}{|c|}{ Anisotropy - Ratio of stress in $\mathrm{L}$ and $\mathrm{L}+45^{\circ} / \mathrm{L}+60^{\circ}$ directions w.r.t } \\
\hline Tensile yield stress & 1.15 & 1.03 & 1.07 & 1.14 \\
\hline Tensile UTS & 1.14 & 1.03 & 1.06 & 1.10 \\
\hline$\%$ Elongation & 57.0 & 50.5 & 79.9 & 86.5 \\
\hline Area of yield locus ellipse, $(\mathrm{MPa})^{2}$ & $3.6 \times 10^{7}$ & $7.2 \times 10^{7}$ & $4.87 \times 10^{7}$ & $7.34 \times 10^{7}$ \\
\hline RMSE & $4.7 \times 10^{4}$ & $7.1 \times 10^{4}$ & $18.1 \times 10^{4}$ & $19.4 \times 10^{4}$ \\
\hline
\end{tabular}

This is because the true yielding on the application of indentation occurs under compression and on the other hand, the tensile yield stresses are only the derived values. Hence, the yield surfaces that are determined from the Knoop microhardness, in general provides the qualitative trends in the nature of yielding; such data should be treated with caution for any specific application or service condition.

The data in tables 3 and 4 clearly indicate the yield stress values determined based on the Knoop microhardness are more than 5 times higher as compared to the yield strength values determined from tensile testing. Such large differences are normally observed and the same has been attributed to the high degree of localized deformation at the surface and also, large degree of friction in case of Knoop indentation (Lee 1973). It is to be noted that the yield locus plots require both tension and compression strength data to qualify the degree and nature of predicted yield behaviour. Such an exercise can be accomplished easily in case of reasonably thick plates and the same is simply not possible for the present thin sheet products for the experimental limitations in obtaining the compressive strength data.

None of the reported studies till date addressed the deformation behaviour, yield loci evaluation and their influence on the drawability in elevated temperature superalloys, such as the Nimonic C-263 sheet metal. These aspects are addressed briefly in the present work. An analyses of the data summarily presented in table 4 indicate the trends in the degree of anisotropy. These data clearly show that the degree of anisotropy is significantly higher for the solution 
treated condition, which values decrease considerably with subsequent aging. The degree of anisotropy in tensile properties (analysed with respect to comparing of properties in L direction with those of LT or $\mathrm{L}+45^{\circ} / \mathrm{L}+60^{\circ}$ ) is nearly $20-30 \%$ higher in the $\mathrm{CR}+\mathrm{ST}$ condition as compared to the peak aged condition. This could be due to the influence of varied dislocation $\gamma$ ' precipitate interaction with or without the additional contribution from the change in texture. Such anisotropy has direct and explicit bearing on the formability, which aspect is explained in detail in a subsequent section. It is desired to have appropriate texture of significant intensity and related anisotropy with lower strengths for formability, while on the other hand, exactly opposite requirements are suitable for sheet structural applications.

\subsection{Strain hardening behaviour}

The experimental true stress - true strain $(\sigma-\varepsilon)$ data for all the conditions, on log-log scale (figure 12) exhibit two-slope behaviour with a gradual transition. Considerable rise in flow stress following aging can be noted from data in figure 12. However, the flow stress, subsequently, decreases with overaging. In addition, the transition strain too was found to vary with aging.

The Ludwigson relationship $\left(\alpha=K_{1} \epsilon_{p}^{n_{1}}+\exp \left(K_{2}+n_{2} \epsilon_{p}\right)\right.$ ) (Ludwigson 1971) provides the best fit of the experimental $\sigma-\varepsilon$ data of the alloy in solution treated as well as the peak aged condition studied at $298 \mathrm{~K}$ (Ankamma et al 2010). The ability of Ludwigson equation for the best description of the flow behaviour, as pointed out by the earlier investigators (Sivaprasad et al 1997), can possibly be attributed to larger number of parameters in the equation as compared to other relationships (which have either two or three parameters). This is because the larger the number of parameters in an equation, the closer will be its approximation to the experimental data. However, it is important to consider the physical significance of the parameters before selecting any empirical equation to fit the data. The advantage of using the Ludwigson equation (Ludwigson 1971) is that it not only accounts for transient flow at low strains but also provides

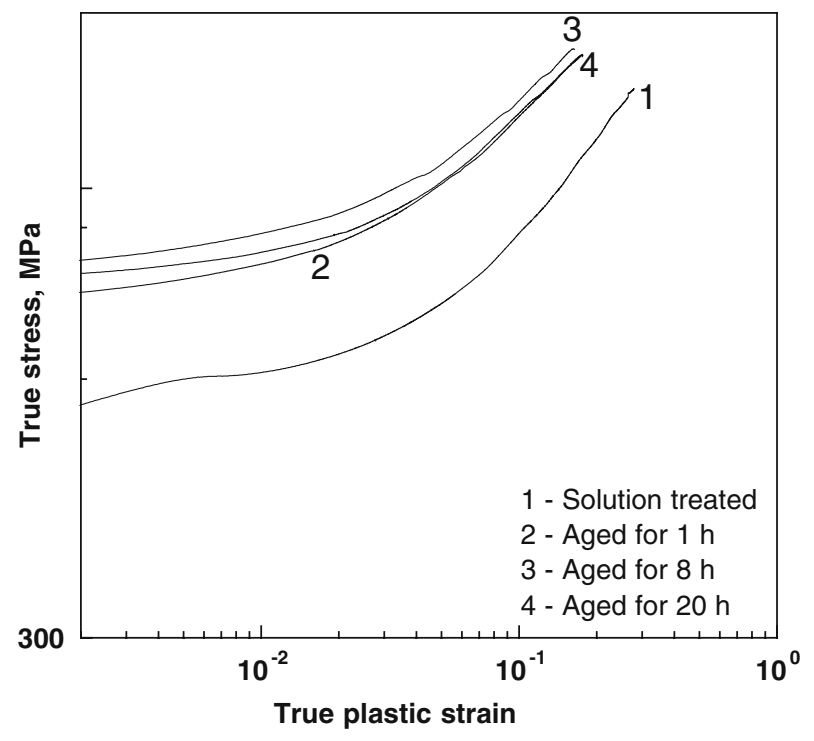

Figure 12. True stress - true plastic strain curves of the Nimonic C-263 alloy sheet of $1.0 \mathrm{~mm}$ thickness in $\mathrm{CR}+\mathrm{ST}$ as well as in different aged conditions (log-log scale). 
Table 5. Summary of flow curve parameters (in Ludwigson equation) of Nimonic C-263 alloy sheet for different aging conditions.

\begin{tabular}{lcccccc}
\hline Heat treatment & Test temperature $(\mathrm{K})$ & $\mathrm{K}_{1}(\mathrm{MPa})$ & $\mathrm{n}_{1}$ & $\mathrm{~K}_{2}$ & $\mathrm{n}_{2}$ & $\varepsilon_{L}$ \\
\hline $1 \mathrm{~mm}$ thickness & \multirow{2}{*}{298} & 2025.4 & 0.35 & 5.58 & -36.70 & 0.080 \\
CR+Solution treated & & 2240.7 & 0.26 & 6.16 & -99.70 & 0.033 \\
Aged for 1 h & & 2337.2 & 0.23 & 6.03 & -113.50 & 0.03 \\
Aged for $8 \mathrm{~h}$ & 2262.3 & 0.27 & 6.11 & -95.40 & 0.045 \\
Aged for 20 h & & & & & & \\
\hline
\end{tabular}

basis for correlation of flow parameters with microstructural parameters (such as precipitate size) and associated substructural changes.

Following the method of Ludwigson (Ludwigson 1971), various flow parameters were determined. It is interesting to note that the Nimonic C-263 alloy even in aged conditions exhibits transient flow behaviour at lower strains, as can be seen from figure 12. A similar behaviour exhibiting transient flow at low strains has also been reported earlier in a $\mathrm{Fe}-\mathrm{Ni}-\mathrm{Cr}-\mathrm{Al}$ alloy strengthened by Ni-Al precipitates (Satyanarayana et al 2004). Further, the data fitted according to this model not only yields a unique set of flow curve parameters for each aging condition (table 5) but also exhibit a systematic trend with aging time. The parameters $\mathrm{K}_{1}, \mathrm{~K}_{2}$ and $\mathrm{n}_{2}$ (-ve) decrease, while the parameters $\mathrm{n}_{1}$ and $\varepsilon_{\mathrm{L}}$ increase with overaging.

Figure 13 illustrates the variation of strain hardening rate, $\theta(=\mathrm{d} \sigma / \mathrm{d} \varepsilon)$ with strain $(\mathrm{a})$ and with stress (b), on log-log scale, for the alloy of $1.0 \mathrm{~mm}$ thickness sheet in solution treated as well as aged conditions. These figures reveal that the alloy in both solution treated and aged conditions exhibit three fairly distinct regimes of strain hardening. Strain hardening rate initially decreases in regime I, remains constant in regime II and then starts decreasing in stage III. Also, as evident from these figures the alloy in aged conditions exhibit higher initial strain hardening rates as compared to the alloy in solution treated condition. However, the strain hardening rate plots for both the solution treated and aged conditions merge at higher strain levels.

(a)

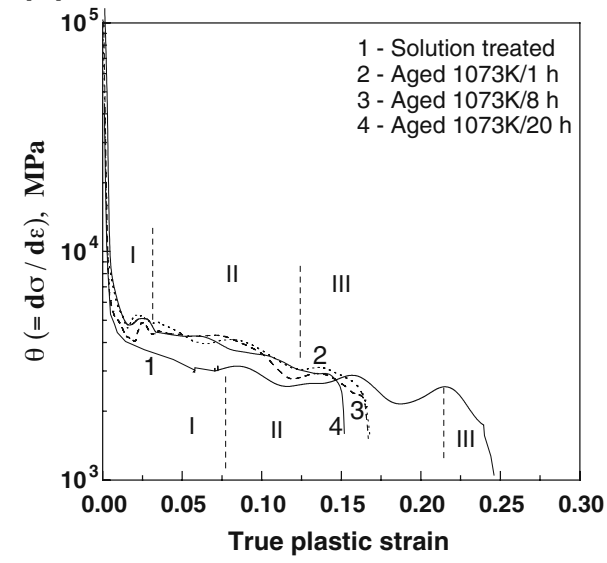

(b)

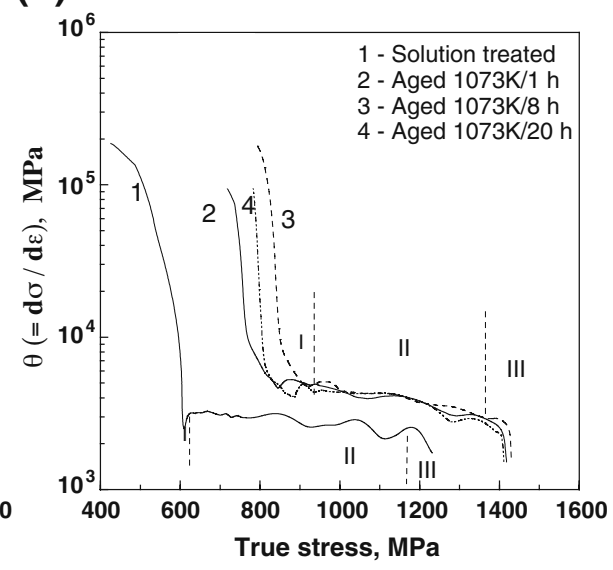

Figure 13. Variation of strain hardening rate $(\theta=d \sigma / d \varepsilon)$ with (a) strain and (b) stress, in case of Nimonic C-263 alloy sheet of $1.0 \mathrm{~mm}$ thickness in CR+ST as well as in different aged conditions. 
In the present study, both $\theta$ vs. $\varepsilon$ (figure 13a) and $\theta$ vs. $\sigma$ (figure 13b) plots, on log-log scale, have been examined and we find that they are quite similar in the sense that both type of plots exhibit three distinct regimes of strain hardening and also, the level of strain hardening rates for different regimes are almost same in either case. They do not exhibit any deviations as reported by Reed-Hill et al (1973). This behaviour is, probably, due to the fact that the alloy used in the present study was subjected to solution treatment at $1473 \mathrm{~K}$ and hence the prior deformation effects are expected to be totally eliminated. Further, as evident from figure 13b, the curves for solution treated as well as different aging conditions are separated for $\theta$ vs. $\sigma$ plots (figure $13 \mathrm{~b}$ ) as compared to $\theta$ vs. $\varepsilon$ plots (figure 13a), at least in regime I. Further, the decrease in level of work hardening with overaging, as indicated by these curves, is more discernible for $\theta$ vs. $\sigma$ (figure $13 \mathrm{~b}$ ) plots. As evident from the $\log \theta$ vs. $\log \varepsilon$ (figure 13a) curve of the alloy in solution treated condition, the first, second and third regimes of strain hardening extend over strain ranges from 0.002 to $0.08,0.08$ to 0.2 and 0.2 to 0.25 respectively. Similar behaviour has also been reported earlier in $\alpha$ - brass and MP $35 \mathrm{~N}$ (35\% Ni-35\% Co-20\% Cr-10\% Mo) alloy deformed under compression (Asgari et al 1997) and precipitation hardenable iron based alloy (Satyanarayana et al 2007). Based on the substructural features reported by earlier investigators (Asgari et al 1997; Satyanarayana et al 2007), in the low stacking fault energy (SFE) alloys, the variation of work hardening rate in the three regimes of the present alloy can be interpreted as follows: the decreasing strain hardening rate in regime $\mathrm{I}$ is due to dynamic recovery (by cross-slip and annihilation of screw components of dislocations) identical to stage III of work hardening of metals of higher SFE, such as copper. The onset of second (II) or constant strain hardening rate regime correlates with the initiation of primary deformation twinning in the microstructure, while the subsequent fall in strain hardening rate during regime III is associated with a decreased rate of primary twin deformation.

The other aspect investigated in the present study is the affect of specimen orientation with respect to rolling direction on strain hardening behaviour of the alloy. Strain hardening rate, $\theta(=\mathrm{d} \sigma / \mathrm{d} \varepsilon)$ versus strain plots for the alloy in solution treated as well as aged conditions and for different specimen orientations are shown in figure 14. As evident from the figure, while the alloy

(a)

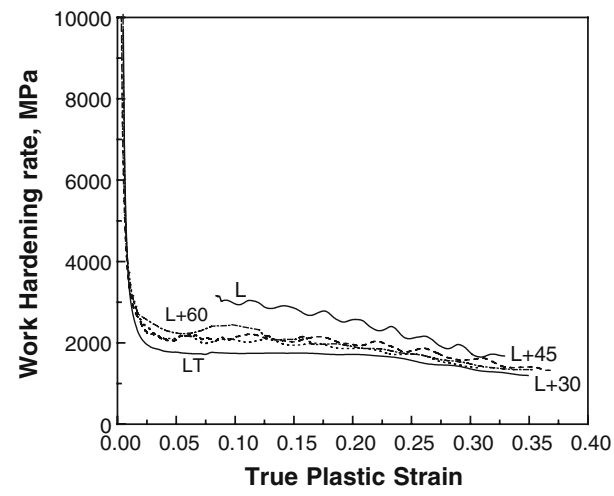

(b)

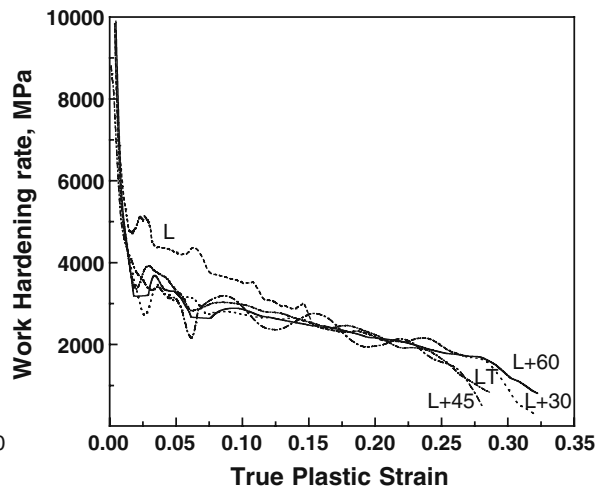

Figure 14. Strain hardening rate $(\theta=d \sigma / d \varepsilon)$ vs strain plots of Nimonic C-263 alloy sheet of $1.0 \mathrm{~mm}$ thickness for different specimen orientations in (a) $\mathrm{CR}+\mathrm{ST}$ and (b) Peak aged (CR+ST+1073 K/8 h aged) conditions. 
specimen with longitudinal orientation (i.e., parallel to rolling direction), exhibit marginally highest strain hardening rates, specimen with long transverse (LT) orientation exhibits lowest strain hardening rate both in solution treated and aged conditions. However, for all other orientations (i.e., $\mathrm{L}+30^{\circ}, \mathrm{L}+45^{\circ}$ and $\mathrm{L}+60^{\circ}$ ), the strain hardening rate data is fairly close and lie in between those of L and LT orientations. Such a behaviour is consistent with the inplane anisotropy, as described in section 3.3 with regard to tensile properties. Further, the sheet thickness variation was found not to effect the nature of work hardening significantly.

\subsection{Drawability: effect of in-plane anisotropy and aging}

The drawability characteristics of Nimonic C-263 alloy sheet is evaluated using LSDYNA with the equation of motion,

$$
[\mathrm{M}]\{\ddot{u}\}+[\mathrm{C}]\{\ddot{u}\}+\left\{f_{\text {int }}\right\}\{\mathrm{u}\}=\{\mathrm{P}(\mathrm{t})\},
$$

where $[\mathrm{M}]$ and $[\mathrm{C}]$ are lumped mass and damping matrices respectively; $\{\ddot{u}\},\{\dot{u}\}$ and $\{\mathrm{u}\}$ are acceleration, velocity and displacement column matrices respectively, is integrated using central difference scheme. $\{\mathrm{P}(\mathrm{t})\}$ is the Net force column matrix and $\left\{f_{\text {int }}\right\}$ is the internal force matrix. The time step is calculated by the code automatically based on shortest characteristic distance of smallest element.

4.3a Material model and properties of tooling: The rigid material type provides a convenient way of turning one or more parts comprised of beams, shells, or solid elements into a rigid body. Approximating a deformable body as a rigid body is a preferred modelling technique in many real world applications. In case of sheet metal forming also, the tooling can be treated as rigid with sufficient accuracy. Elements which are rigid, are bypassed in the element processing and no separate provision is made for storing history variables; consequently, the rigid material type is cost-efficient. Inertial properties for rigid materials may be defined in either of two ways. By default, the inertial properties are calculated from the geometry of the constituent elements of the rigid material and the density specified for the part ID. Alternatively, the inertial properties and initial velocities for a rigid body may be directly defined, and this overrides data calculated from the material property definition and nodal initial velocity definitions. In this work, the mass density ' $\rho$ ' is defined for the calculation of inertial properties. Young's modulus (E), and Poisson's ratio, are used for determining sliding interface parameters if the rigid body interacts in a contact definition. Since, in this work contact is defined between punch and blank, die and blank and blank holder and blank, the properties of Young's modules and Poisson's ratio are required to be defined. The material properties selected for punch, die and blank holder correspond to any typical die steel and the values taken are; Young's modulus (E) - $200 \mathrm{GPa}$, Poisson's ratio $(\mu)-0.3$ and density $(\rho)-7900 \mathrm{Kg} / \mathrm{m}^{3}$.

4.3b Material model for the blank material: LS DYNA 970 has 134 material models, out of which, the one where the material property data fits the best, is selected. The anisotropy of a sheet metal during sheet forming is a combination of the initial anisotropy due to its previous history of thermo-mechanical processing and due to the plastic deformation during forming. The former leads to symmetry with orthotropic character while the later called as deformation-induced anisotropy can destroy this symmetry when principal material symmetry and deformation axes are not superimposed. Therefore, modelling of plastic anisotropy itself and its implementation in 
finite element code can be complex. Moreover, the data needed to capture deformation-induced anisotropy is rarely available, particularly for industrial application.

For practical purposes, the assumption that the change of anisotropic properties during sheet metal forming is small and negligible when compared to anisotropy-induced by cold rolling and heat treatment, which is widely accepted. Therefore, when plastic deformation is moderate, a simple description of anisotropy based on experimental data as input might be adequately accurate for sheet metal forming simulation rather than more sophisticated anisotropy model (Jeong-Whan et al 2004). So, the material models which take the initial anisotropy into account such as Barlat's 3-parameter plasticity model (Barlat \& Lian 1989). and anisotropic plasticity model (Barlat et al 1991a, b). Here, Barlat's 3-parameter plasticity model is chosen for this work. The yield function $(\phi)$, used in Barlat's model is given as

$$
\phi=a\left|K_{1}+K_{2}\right|^{m}+a\left|K_{1}-K_{2}\right|^{m}+c\left|2 K_{2}\right|^{m}=2 \sigma_{y}^{m},
$$

where $\sigma_{y}$ is the current effective stress, $\mathrm{K}$ is strength coefficient and the exponent ' $\mathrm{m}$ ' is taken as 8 for fcc metals (Jhon 1998) and $\mathrm{K}_{1}$ and $\mathrm{K}_{2}$ are given by

$$
\begin{gathered}
K_{1}=\frac{\sigma_{x}+h \sigma_{y}}{2} \\
K_{2}=\sqrt{\left(\frac{\sigma_{x}-h \sigma_{y}}{2}\right)^{2}+P^{2} \tau_{x y}^{2}}
\end{gathered}
$$

with the hardening function

$$
\sigma_{y}=K\left(\varepsilon_{p}+\varepsilon_{0}\right)^{n}
$$

where $\varepsilon_{\mathrm{p}}$ is the plastic strain $\varepsilon_{0}$ is the initial yield strain and $\mathrm{n}$ is the strain hardening index.

Table 6. The material properties of Nimonic C-263 alloy.

\begin{tabular}{llll}
\hline S.No & \multicolumn{1}{c}{ Material property } & \multicolumn{2}{c}{ Material condition } \\
\cline { 3 - 4 } & & \multicolumn{1}{c}{$(\mathrm{CR}+\mathrm{ST})$} & Peak aged $(\mathrm{CR}+\mathrm{ST}+1073 \mathrm{~K} / 8 \mathrm{~h}$ aged $)$ \\
\hline 1. & Density & $8.36 \mathrm{~g} / \mathrm{cm}^{3}$ & $8.36 \mathrm{~g} / \mathrm{cm}^{3}$ \\
2. & Young's modulus & $217.25 \mathrm{GPa}$ & $220.40 \mathrm{GPa}$ \\
3. & Poison's ratio & 0.3053 & 0.3036 \\
4. & Strength coefficient, $\mathrm{K}$ & 2025.4 & 2190.2 \\
5. & Strain hardening Index, $\mathrm{n}$ & 0.35 & 0.233 \\
6. & UTS (true stress) & $1231 \mathrm{MPa}$ & $1451 \mathrm{MPa}$ \\
7. & Yield strain & 0.00492 & 0.00788 \\
8. & $\mathrm{R}_{0}$ & 2.20 & 1.45 \\
9. & $\mathrm{R}_{45}$ & 2.03 & 1.35 \\
10. & $\mathrm{R}_{90}$ & 2.12 & 1.18 \\
\hline
\end{tabular}


The anisotropic material constants a, $\mathrm{c}$ and $\mathrm{h}$ in Eqs. 5-8, are obtained through $\mathrm{R}_{00}$ and $\mathrm{R}_{90}$ as;

$$
\begin{gathered}
a=2-2 \sqrt{\frac{R_{00} R_{90}}{\left(1+R_{00}\right)\left(1+R_{90}\right)}}, \\
c=2-a, \\
h=\sqrt{\frac{R_{00}\left(1+R_{90}\right)}{R_{90}\left(1+R_{00}\right)}} .
\end{gathered}
$$

The material properties required for the numerical simulation are obtained from the tensile testing and are given in table 6 . The data given in table 6 are described in terms of aging effects

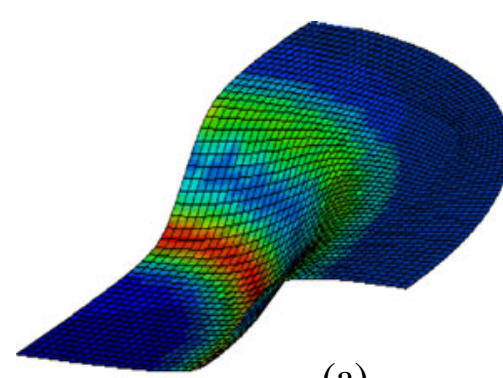

(a)

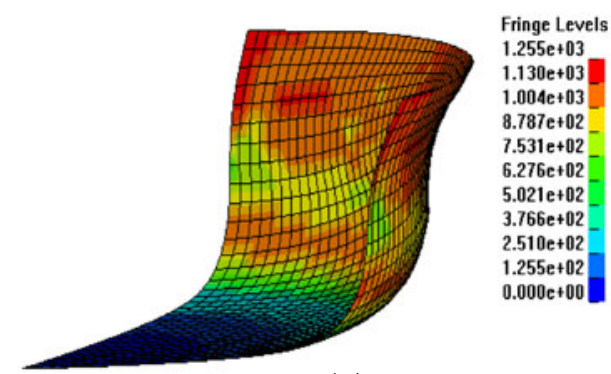

(c)

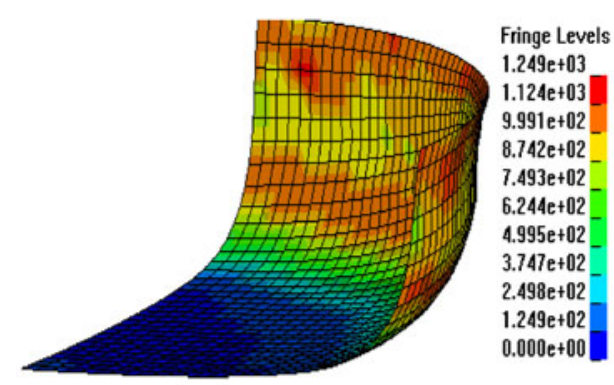

(e)

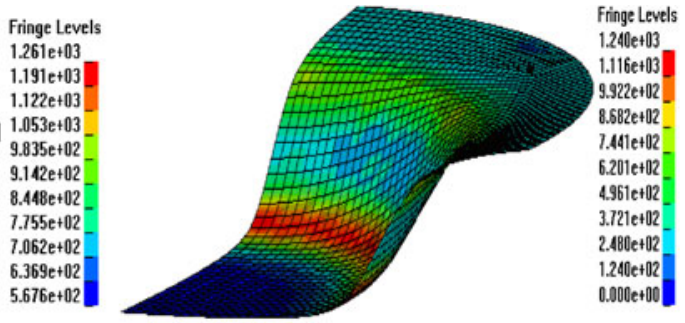

(b)

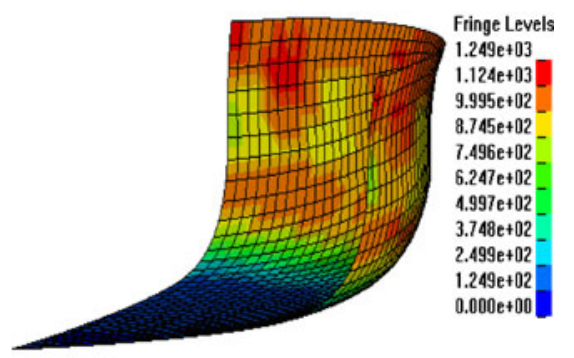

(d)

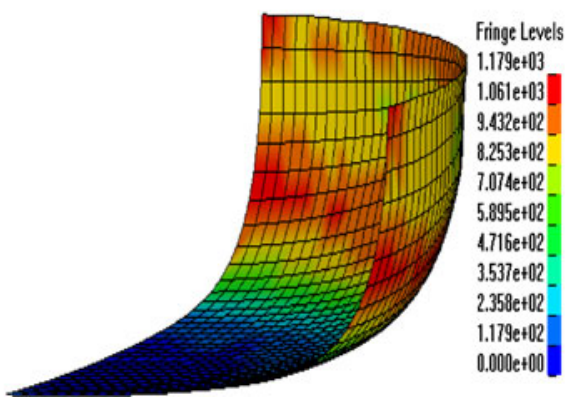

(f)

Figure 15. Effective stress distribution for (a) $\beta=2.0$, (b) $\beta=1.8$, (c) $\beta=1.5$, (d) $\beta=1.4$, (e) $\beta=1.35$ and (f) $\beta=1.3$ of the Nimonic C-263 alloy sheet of $1.0 \mathrm{~mm}$ thickness in CR+ST condition for a friction factor of 0.015 . 
(figure 9). However, it should be noted that the derived values of $\mathrm{R}$ namely $\mathrm{R}_{00}, \mathrm{R}_{45}$ and $\mathrm{R}_{90}$ are significantly higher in $\mathrm{CR}+$ solution treated condition (2.1 to 2.2) as compared to peak aged condition (the variation is slightly higher ranging from 1.1 to 1.5). The variation of true stress with true plastic strain as shown in figure 12 is used as basic data inputs for the numerical analysis.

4.3c Simulation for limit drawing ratio: Simulations are carried out iteratively to find the limit drawing ratio (LDR) of the Nimonic C-263 alloy sheet in CR+ST and peak aged conditions as per the following procedure. If the maximum effective stress > UTS (1231 MPa for $\mathrm{CR}+$ solution treated and $1451 \mathrm{MPa}$ for peak aged condition), drawing ratio is reduced, or else increased. The simulations are carried out till the maximum drawing ratio, where maximum effective stress lesser than UTS is obtained. Figure 15 shows the effective stress distribution for the $\mathrm{CR}+$ solution treated sample of Nimonic C-263 alloy sheet. Figures 15 a to d, show that maximum effective stress for the drawing ratio ( $\beta$ values of $2,1.8,1.5$ and 1.4 crossed UTS of the material in the middle of the drawing process itself. From the simulation figures $15 \mathrm{e}$ and $\mathrm{f}$, it can be seen that maximum effective stress has not exceeded the UTS throughout the drawing process for drawing ratio 1.3 and it is slightly more than UTS for the drawing ratio 1.35. Hence LDR is in between 1.3 and 1.35 for this material with the friction factor 0.015 in CR + solution treated condition. A series of tests conducted by Siegert and co-workers (Siegert \& Wagner 1994) on non-heat treatable aluminum alloy (EN-AW-5182-O) showed that LDR strongly depends on the friction factor between the flange region of the cup and blank holder. Jurkovic and co-workers (Jurkovic 2006) have experimentally determined friction coefficients in deep drawing for various surface conditions of tooling at different degrees of deformation. They vary from 0.015 to 0.20 . Hence the effect of friction factor on the LDR of the present Nimonic C-263 alloy sheet is evaluated at these two extreme friction factor values.

The simulations in the present study are carried out with various friction factors between 0.015 and 0.20 and observed that the there is no significant variation of LDR with respect to coefficient of friction. The safe (effective stress $<$ UTS) and unsafe (effective stress $>$ UTS) regions for cup

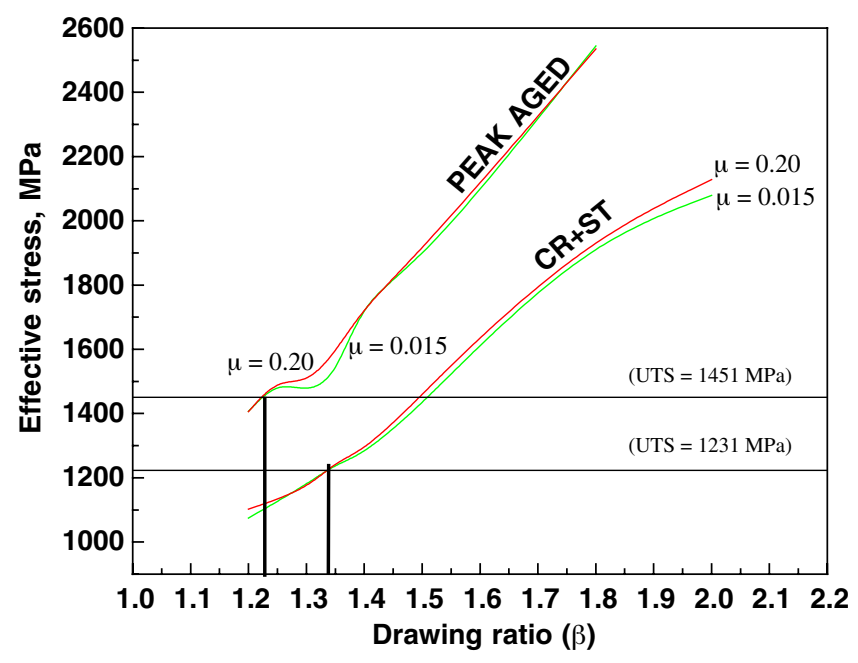

Figure 16. Variation of effective stress with drawing ratio for two different frictional coefficients of 0.015 and 0.20 for cup formation/drawability of the alloy in CR+ST and in peak aged (CR+ST+1073 K/8 h aged) conditions. 
formation for the friction factors 0.015 and 0.20 are shown in figure 16 . The data in figure 16 show that in this alloy sheet the variation in maximum effective stress is negligibly small for different friction coefficient $(\mu)$ values. It is also noted from the data in figure 16 that the LDR of the material is unchanged with the friction coefficient for this alloy in CR + solution treated condition and is thus determined to be 1.33 .

Figure 17 shows the effective stress distribution of Nimonic C-263 alloy sheet in the peak aged condition. Figures 17 a to d, show that maximum effective stress for the drawing ratio $(\beta)$ values of $2,1.8,1.5$ and 1.4 crossed UTS of the material in the middle of the drawing process itself. From the simulation figures $17 \mathrm{e}$ and $\mathrm{f}$, it can be seen that maximum effective stress has not exceeded the UTS throughout the drawing process for drawing ratio 1.2 and it is more than UTS for the drawing ratio 1.25. Hence LDR is in between 1.2 and 1.25 for this material with the friction factor 0.015 . The simulations are carried out with various friction factors between 0.015 and 0.20 and observed that there is no significant variation of LDR with respect to coefficient of friction.

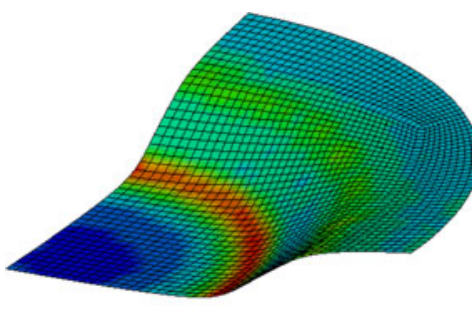

(a)

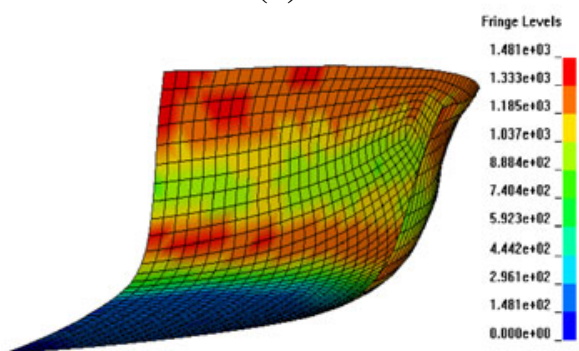

(c)

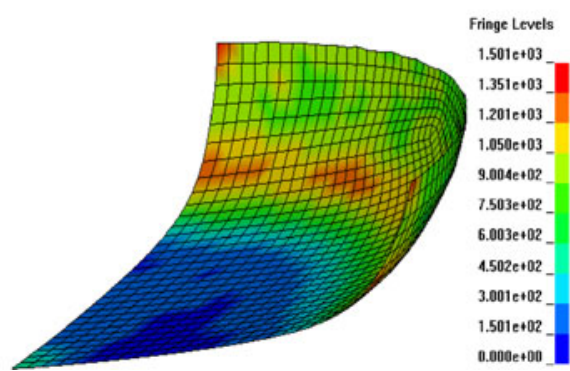

(e)

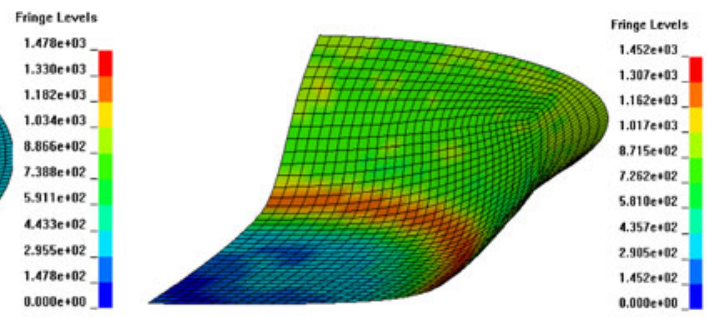

(b)

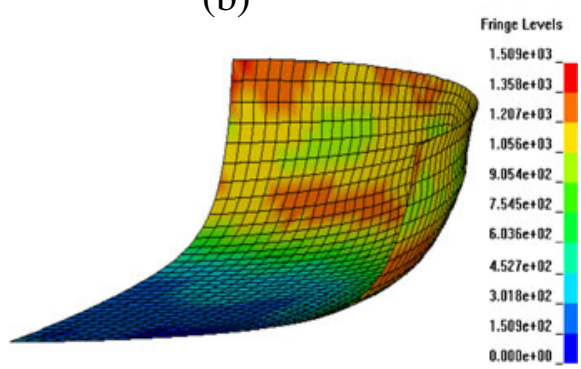

(d)

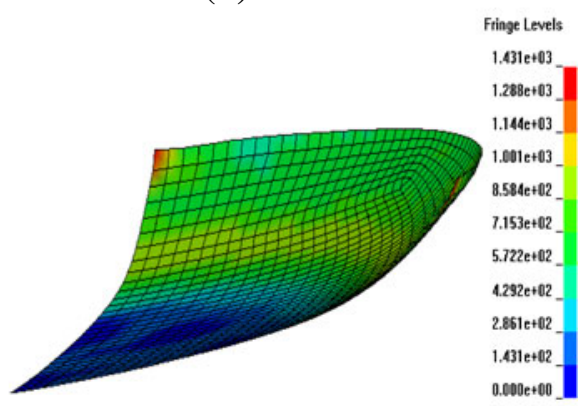

(f)

Figure 17. Effective stress distribution for (a) $\beta=1.8$, (b) $\beta=1.5$, (c) $\beta=1.4$, (d) $\beta=1.3$, (e) $\beta=1.25$ and (f) $\beta=1.2$ of the Nimonic C-263 alloy sheet of $1.0 \mathrm{~mm}$ thickness in peak aged $(\mathrm{CR}+\mathrm{ST}+1073 \mathrm{~K} / 8 \mathrm{~h}$ aged $)$ condition for a friction factor of 0.015 . 
The safe (effective stress < UTS) and unsafe (effective stress $>$ UTS) regions for cup formation for the friction factors 0.015 and 0.20 of the alloy in the peak aged condition are included in figure 16. The data in figure 16 show that in this alloy sheet the variation in maximum effective stress is again negligibly small for different friction coefficient $(\mu)$ values. Thus the LDR of the material is unchanged with the friction coefficient for this alloy in peak aged condition and is observed to be 1.23 .

4.3d Simulation for determination of limit strains: Simulations are carried out iteratively to find out the limit strains of the Nimonic C-263 alloy sheet of $1.0 \mathrm{~mm}$ thickness in CR+ST and peak aged conditions as per the following procedure. Since failure criteria is not specified for the material model used in the present work, the failure can not be seen. The cup is being drawn continuously, even after the effective stress becomes more than the UTS (true stress) of the material. So, the simulation is run till the maximum effective stress crosses the UTS and the nodal results of that state are output to a file. From these nodal results, the node numbers for which the effective stress nearer to UTS up to an accuracy of $\pm 0.2 \mathrm{MPa}$ (i.e., $1231 \pm$ $0.2 \mathrm{MPa}$ for ST condition and $1451 \pm 0.2 \mathrm{MPa}$ for peak aged condition) are noted. Then nodal results of the principal strains of that state are written to another file and the principal strain values of the nodes, whose effective stress is within the range specified above are noted. These principal strains are termed as 'limit strains'. The simulations are continued till sufficient data is collected for plotting Forming Limit Curves (FLC's) and the same is presented in figure 18. The data in figure 18 show the regions of safe and unsafe deformation in general and drawability in particular.

It is observed that the effective stress crosses the UTS at the punch corner where the state of stress is biaxial tension (Dieter 1988) (corresponding to plane stress condition). Hence, only right hand side of FLC is obtained. The data from figure 18 show that the safer limits for deformation after aging of the alloy is lesser than that of $\mathrm{CR}+\mathrm{ST}$ condition.

In order to bring out the effects of aging on limit strains, the limit strain parameters of the alloy sheet in the two heat treatment conditions are included in table 7. The data in table 7 grossly predict that the limit strain values (major and minor) are quite similar to the CR+ST and peak aged conditions. However, the limit stress values obtained from the stress-based analysis

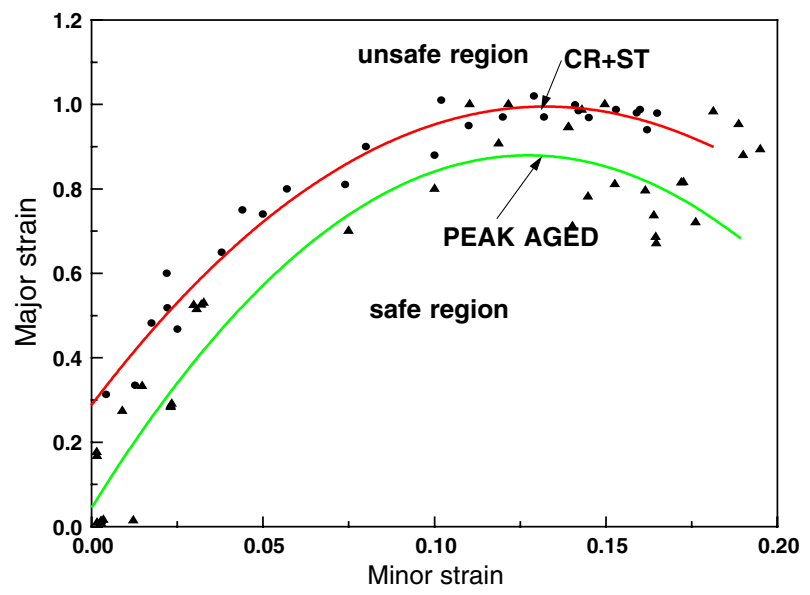

Figure 18. Forming limit curve for Nimonic C-263 alloy of $1.0 \mathrm{~mm}$ thickness in CR+ST and peak aged $(\mathrm{CR}+\mathrm{ST}+1073 \mathrm{~K} / 8 \mathrm{~h}$ aged) conditions. 
Table 7. A summary on the effect of aging on the LDR and limit strain predictions in Nimonic C-263 alloy sheet.

\begin{tabular}{lcc}
\hline Property & \multicolumn{2}{c}{ Values in } \\
\cline { 2 - 3 } & $\mathrm{CR}+\mathrm{ST}$ & Peak aged $(\mathrm{CR}+\mathrm{ST}+1073 \mathrm{~K} / 8 \mathrm{~h})$ \\
\hline 1. Limit drawing ratio & $1.30-1.35$ & $1.20-1.25$ \\
2. Major strain & $0.9-1.0$ & $0.8-0.9$ \\
3. Minor strain & $0.17-0.18$ & $0.18-0.19$ \\
4. Major stress, $\mathrm{MPa}$ & $1280-1320$ & $1500-1600$ \\
5. Minor stress, MPa & $600-650$ & $900-1000$ \\
\hline
\end{tabular}

are significantly higher for the peak aged condition. This clearly points the fact that though the nature of deformation is not significantly different in both aged conditions, the same deformation processes presumably occur at higher stresses for the relatively high strength peak aged sheets.

Since this method of determining limit strain values used in the present study is proposed for the first time, the method is to be validated for its correctness. The validation is carried out using the vertex theory developed by Storen \& Rice (1975) and modified by Zhu and co-workers (Zhu et al 2001) and the forming limits are derived by Jie and co-workers (Jie et al 2007) for the material with power law plasticity model with Hosford's yield criterion. The same is presented in the following equations.

For left hand side of FLD the forming limit strain is

$$
\varepsilon^{*}=\frac{\left(1+R_{0}\right)\left[r_{\sigma}^{a-2}+R_{90}\left(1+r_{\varepsilon}\right)\left(1-r_{\sigma}\right)^{a-2}\right] f\left(r_{\sigma}\right)}{(a-1)\left(1+r_{\varepsilon}\right)\left(1+r_{\varepsilon} r_{\sigma}\right)\left[r_{\sigma}^{a-2}+\left(R_{90}+R_{0} r_{\sigma}^{a-2}\right)\left(1-r_{\sigma}\right)^{a-2}\right]}+\frac{(a-1) n-1}{(a-1)\left(1+r_{\varepsilon}\right)} .
$$

For the right hand side of the FLD

$$
\varepsilon^{*}=\frac{\left(1+R_{0}\right)\left[r_{\sigma}^{a-2}+R_{90}\left(1-r_{\sigma}\right)^{a-2}\right] f\left(r_{\sigma}\right)}{(a-1)\left(1+r_{\varepsilon} r_{\sigma}\right)\left[r_{\sigma}^{a-2}+\left(R_{90}+R_{0} r_{\sigma}^{a-2}\right)\left(1-r_{\sigma}\right)^{a-2}\right]}+\frac{(a-1) n-1}{(a-1)\left(1+r_{\sigma} r_{\varepsilon}\right)},
$$

where $\mathrm{R}_{0}$ and $\mathrm{R}_{90}$ are the ratio of transverse strain to thickness strain under uniaxial tension along the rolling direction and the transverse direction respectively. $\varepsilon^{*}$ is the ultimate strain in uniaxial tensile test, $\mathrm{r}_{\varepsilon}$ and $\mathrm{r}_{\sigma}$ are strain ratio and stress ratio respectively. ' $\mathrm{n}$ ' is strain hardening index and ' $\mathrm{a}$ ' is exponent in Hosford's yield criterion (the value of a is taken as 8 for fcc metals) and

$$
f\left(r_{\sigma}\right)=\frac{1}{\left[R_{90}\left(1+R_{0}\right)\right]^{\frac{1}{a}}}\left[R_{90}+\frac{R_{0}}{r_{\sigma}^{a}}+\frac{R_{0} R_{90}}{\left(1-r_{\sigma}\right)^{a}}\right]^{\frac{1}{a}} .
$$

The instability occurs at $\frac{d \sigma}{d \varepsilon}=\sigma$, by solving which the condition for the ultimate strain for the constitutive law $\sigma_{y}=K\left(\varepsilon_{P}+\varepsilon_{0}\right)^{n}$ is

$$
\varepsilon^{*}=n .
$$

The ultimate strain i.e., $\varepsilon^{*}$ is calculated substituting the values obtained from the simulation in equation 13 and compared with the equation 15. The error and \% error in ultimate strains are computed. It is seen that, the error is with in the range of $+10 \%$ and the values from the simulation have been found to tally with those calculated from the analytical formulae (see the data in table 8). It shows that the proposed method adopted for finding out limit strains is sufficiently accurate and treated to be validated. It should be noted here that, similar conclusions are drawn from the data obtained for the alloy sheet in the peak aged condition as well. 
Table 8. Comparison of the ultimate strain values obtained from vertex theory and with the constitutive law for the Nimonic C-263 alloy of $1.0 \mathrm{~mm}$ thickness in cold rolled and solution treated condition.

\begin{tabular}{lllcccrr}
\hline S.No & $\begin{array}{c}\text { Major } \\
\text { strain }\left(\varepsilon_{1}\right)\end{array}$ & $\begin{array}{c}\text { Minor } \\
\text { strain }\left(\varepsilon_{2}\right)\end{array}$ & $\begin{array}{c}\text { Limiting } \\
\text { major stress } \\
\left(\sigma_{1}\right)(\mathrm{MPa})\end{array}$ & $\begin{array}{c}\text { Limiting } \\
\text { minor stress } \\
\left(\sigma_{2}\right)(\mathrm{MPa})\end{array}$ & $\begin{array}{c}\text { Ultimate strain } \\
\text { from equation } \\
(13)\left(\varepsilon^{*}\right)\end{array}$ & Error & \% Error \\
\hline 1. & 0.313 & 0.00428 & 1279 & 150 & 0.3752 & -0.0252 & -7.20 \\
2. & 0.482 & 0.0175 & 1337 & 275 & 0.3207 & 0.0292 & 8.36 \\
3. & 0.98 & 0.159 & 1350 & 568 & 0.3239 & 0.0260 & 7.44 \\
4. & 0.988 & 0.153 & 1388 & 557 & 0.3349 & 0.0150 & 4.29 \\
5. & 0.985 & 0.142 & 1324 & 509 & 0.3389 & 0.0110 & 3.14 \\
6. & 0.988 & 0.16 & 1351 & 542 & 0.3460 & 0.0039 & 1.13 \\
7. & 1.01 & 0.102 & 1164 & 393 & 0.3184 & 0.0315 & 9.02 \\
8. & 0.518 & 0.0221 & 1307 & 288 & 0.3259 & 0.0240 & 6.88 \\
9. & 0.979 & 0.165 & 1385 & 578 & 0.3366 & 0.0133 & 3.81 \\
10. & 1.02 & 0.129 & 1364 & 499 & 0.3322 & 0.0177 & 5.05 \\
\hline
\end{tabular}

4.3e Determination of stress-based forming limit curves: Experimental results of Graf \& Hosford (1993a, b, 1994) showed that changes in strain path during the deformation change the forming limits which differ from those obtained from linear strain paths. A similar conclusion was obtained from experiments reported by Hance et al (1997). As a remedy to the variation of FLC with the variation of strain path, stress-based forming limit curves called as Forming Stress Limit Curves (FSLC) were proposed by several investigators (Marin et al 1953; Embury \& LeRoy 1977; Arrieux et al 1982; Gronostajski 1984; Arrieux 1995). Stoughton (2000) made a convincing case for the use of the FSLC. He assumed a constitutive model with isotropic hardening and then transformed the FLC into principal stress space. He also showed that the FLCs of the as-received sheet and the pre-strained sheet were mapped to a nearly coincidental curve in

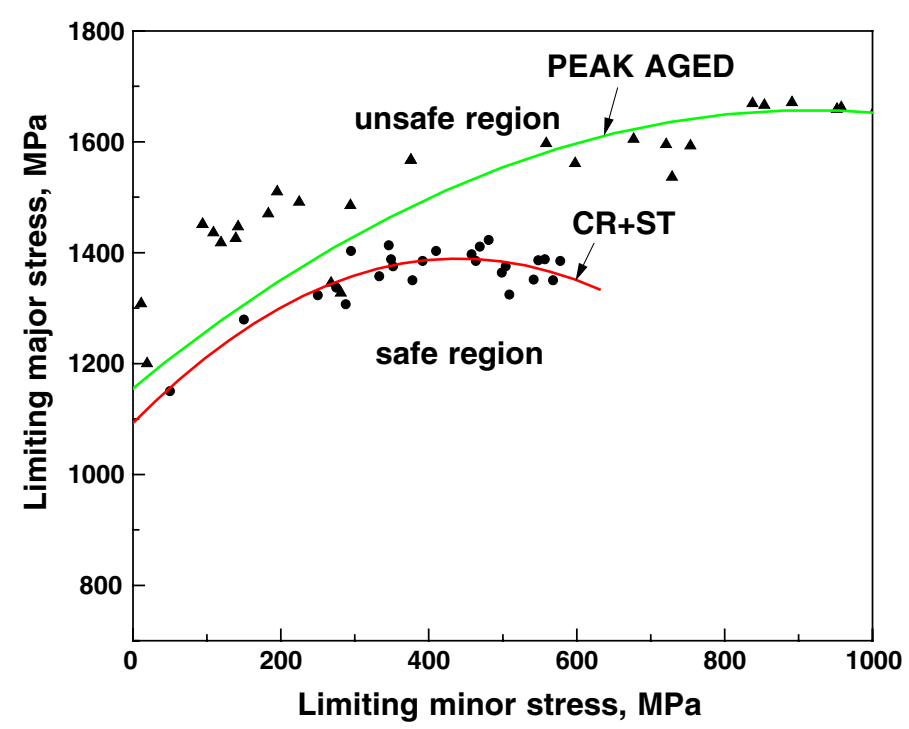

Figure 19. Forming stress limit curve for Nimonic C-263 alloy of $1.0 \mathrm{~mm}$ thickness in CR+ST and peak aged $\mathrm{CR}+\mathrm{ST}+1073 \mathrm{~K} / 8 \mathrm{~h}$ aged) conditions. 
principal stress space. That is, there exists, within the scope of the assumptions made and within the limits of experimental uncertainty, a single curve that represents the limit of formability of the sheet. This FSLC is then geared toward predicting the onset of necking in sheet metal that is subjected to nonlinear load paths.

A theoretical basis for the FSLC was provided by Stoughton \& Zhu (2004) who started with theoretical models for the FSLC and demonstrated path independence in stress space. Stoughton \& Yoon (2005), proposed FSLCs that account for the orientation dependence of strength. Even though the stress-based limit curve obtained is considered having good accuracy as an intrinsic curve that defines the forming limit independent of the strain paths, the limit curves, in stress space, are nearly coincidental because of the lack of sensitivity of the stress-strain relationship at sufficiently large strains. Stoughton (2001), addressed this by showing that when the FLC of Al 2008-T4 was shifted by about $10 \%$, the FSLC was shifted by about $5 \mathrm{MPa}$. Hence FSLC for Nimonic C-263 alloy is calculated and presented in figure 19. The data in figure 19 clearly demarcate the safe and unsafe regions for forming and it is observed that the safer limits of deformation are higher for $\mathrm{CR}+$ Solution treated condition than that of peak aged $(\mathrm{CR}+\mathrm{ST}+1073 \mathrm{~K} / 8 \mathrm{~h}$ aged) conditioned sample in contrary to the forming limit curve based on limit strains. This may be due to higher strength of the peak aged alloy than CR+ST alloy.

\section{Conclusions}

Despite weak crystallographic texture and excellent ductility and high work hardening exponents, the alloy sheet C-263 exhibits significant extent of in-plane anisotropy in its tensile properties and yield loci. The microstructural features, mainly such as precipitation of $\gamma$ ' strengthening phase obtainable by aging after cold rolling and solution treated, was found not to alter the nature of deformation significantly. However the alloy in aged condition shows reduced degree of anisotropy with significantly improved strength characteristics and moderate decrease in drawability. Apart from these major findings, the thesis provides several significant scientific results leading to the following conclusions:

(i) The alloy sheets of both 1.0 and $0.5 \mathrm{~mm}$ thicknesses exhibit similar microstructure and texture. The average grain size is $30 \mu \mathrm{m}$ with high density of deformation twins. Aging has resulted in the copious precipitation of uniformly distributed $\gamma^{\prime}\left(\mathrm{Ni}_{3}(\mathrm{Al}, \mathrm{Ti})\right)$ phase and the alloy sheet in both $\mathrm{CR}+\mathrm{ST}$ and peak aged $(\mathrm{CR}+\mathrm{ST}+1073 \mathrm{~K} / 8 \mathrm{~h}$ aged) conditions contains both coarse $\mathrm{MC}$ and fine $\mathrm{M}_{23} \mathrm{C}_{6}$ type carbides.

(ii) The aged alloy sheets exhibited higher strength levels $(0.2 \%$ YS, UTS, KHN, strengths from yield locus), lower ductility (\% elongation) as well as lower degrees of work hardening exponents (n values and $\theta$ values) and most importantly lower degrees of in-plane anisotropy as compared to those in $\mathrm{CR}+\mathrm{ST}$ condition. In both $\mathrm{CR}+\mathrm{ST}$ and peak aged conditions, the alloy sheet exhibits decrease in yield and ultimate tensile strengths and increase in ductility as the orientation of the tensile specimen axis increases $0^{\circ}$ to $60^{\circ}$ from the rolling direction and further increase in orientation has no specific effect on the tensile properties.

(iii) The absolute magnitudes of yield stress and the exact nature of anisotropy that can be predicted from the tensile part of the yield locus need to be employed with caution as the magnitudes of the yield stresses, obtained from yield locus are more than 5 times higher as compared to the yield and ultimate tensile strength values and the nature and degree of in-plane anisotropy under tensile loading matches with that of only the compressive yield stresses of yield locus. 
(iv) Although aging does not appear to alter the macroscopic flow behaviour, it causes considerable change in various flow parameters and substructural evolution.

(v) The alloy in longitudinal orientation (i.e., parallel to rolling direction, L), exhibits higher strain hardening rates as compared to the long transverse (LT) orientation in both solution treated and aged conditions. However, for all other orientations (i.e., $\mathrm{L}+30^{\circ}, \mathrm{L}+45^{\circ}$ and $\mathrm{L}+60^{\circ}$ ), the strain hardening rate data are fairly close and lie in between those of $\mathrm{L}$ and LT orientations.

(vi) The limit drawing ratio of this alloy is investigated and is found to be quite 'low' in both $\mathrm{CR}+\mathrm{ST}$ condition (1.34) and peak aged (1.23) condition. Unlike the results of previous research works, the effect of friction coefficient on the limit drawing ratio in case of the present Nimonic C-263 alloy sheet is found to be negligibly small. The study thus conducted reveals that the safer forming limits in strain space is higher for $\mathrm{CR}+\mathrm{ST}$ condition; while, the safer forming limits in stress space are higher for peak aged $(\mathrm{CR}+\mathrm{ST}+1073 \mathrm{~K} / 8 \mathrm{~h}$ aged) condition.

The authors are grateful to Shri M Raghavaiah, Former General Manager, Midhani for his help in procuring the material. Sincere thanks are due to Dr. G Malakondaiah, Scientist and Director, Defense Metallurgical Research Laboratory (DMRL) for his permission to use the facilities at DMRL. The authors would like to thank Dr. K S Prasad and Dr. A K Singh for the help in optical micrography and texture analysis, respectively. The authors also would like to thank Shri D S K Murali and Shri R Sekhar Babu for the help in the conduct of tensile testing at DMRL.

\section{References}

Ankamma K, Satyanarayana D V V, Rajdeep Sarkar, Chandramohan Reddy G, Komaraiah M, Eswara Prasad N (inprint) 2010 Effect of aging on the work hardening behaviour of a cold rolled Nimonic C - 263 alloy. Mater. Sci. Technol. doi:10.1179/026708310X12701095964649

Arrieux R 1995 Determination and use of the forming limit stress diagrams in sheet metal forming. $J$. Mater. Process. Technol. 53: 47-56

Arrieux R, Bedrin C, Boivin M 1982 Determination of an intrinsic forming limit stress diagram for isotropic sheets. Proceeding of the $12^{\text {th }}$ IDDRG Congress 2: 61-71

Asgari S, El-Danaf E, Kalidindi S R, Doherty R D 1997 Strain hardening regimes and microstructural evolution large strain compression of low stacking fault energy FCC alloys that form deformation twins. Metall. Trans. A 28A: 1781-1795

Banabic D, Dannenmann E 2001 Prediction of the influence of yield locus on the limit strains in sheet metals. J. Mater. Process. Technol. 109: 9-12

Banabic D, Kuwabara T, Balan T, Cosma 2004 An anisotropic yield criterion for sheet metals. J. Mater. Process. Technol. 157-158: 462-465

Barlat F, Chung K 1993 Anisotropic potentials for plastically deforming metals. Model. Simul. Mater. Sci. Eng. 1: 403-416

Barlat F, Lian J 1989 Plastic behaviour and strecthability of sheet metals Part-1: A yield function of orthotropic sheets under plane strain conditions. Int. J. Plasticity 5: 51-66

Barlat F, Liu J 1998 Precipitate-induced anisotropy in binary Al-Cu alloys. Mater. Sci. Eng. A257: 47-61

Barlat F, Lege D J, Brem J C 1991a A six component yield function for anisotropic materials. Int. J. Plast. 7: 693-712

Barlat F, Lege D J, Brem J C, Warren C J 1991b Texture and anisotropy of an Al-Li alloy. Textures Microstruct. 14-18: 1013-1018 
Cazacu O, Barlat F 2003 Application of the theory of representation to describe yielding of anisotropic aluminium alloy. Int. J. Eng. Sci. 41: 1367-1385

Dieter G E 1988 Mechanical metallurgy. London: McGraw Hill Book Co

Embury J D, LeRoy G H 1977 Failure maps applied to metal deformation processes. Advances in research on the strength and fracture of materials, 15-42

Graf A, Hosford W F 1993a Effects of changing in strain paths on forming limit diagrams of AL 2008-T4. Metallurgical Transactions 24: 2503-2512

Graf A, Hosford W F 1993b Calculations of forming limit diagrams for changing strain paths. Metallurgical Transactions 24: 2497-2501

Graf A, Hosford W F 1994 The influence of strain path changes on forming limit diagrams of AL6111- T4. Int. J. Mech. Sci. 36: 897-910

Gronostajski J 1984 Sheet metal forming limits for complex strain paths. J. Metal Working Technol. 10: 349-362

Hance B M, Foley R P, Matlock D K 1997 Effects of strain path on formability and microstructural evolution in low-carbon sheet steels. SAE paper 970155

Hu W 2003 Characterized behaviors and corresponding yield criterion of anisotropic sheet metals. Mater. Sci. Eng. 345: 139-144

Humphreys F J, Hatherly M 1995 Recrystallization and related annealing phenomena. Oxford: Pergamon, UK

Jeong-Whan Y, Frederic B, Robert E D, Kwansoo C, Tae J K 2004 Plane stress yield function for aluminum alloy sheets, Part II : FE formulation and its implementation. Int. J. Plastic. 20: 495-522

Jhon O H 1998 LS-DYNA Theory manual. Livermore, California: Livermore software technology corporation

Jie M, Cheng C H, Chan L C, Chow C L, Tang C Y 2007 Experimental and theoretical analysis on formability of aluminum tailor welded blanks. J. Eng. Mater. Technol. 129: 151-158

Jurkovic M 2006 The tribological state test in metal forming processes using experiment and modeling. J. Achievements in Materials and Manufacturing Eng. 18: 383-386

Kuwabara T, Bael A V, lizuka E 2002 Measurement and analysis of yield locus and work hardening characteristics of steel sheets with different r-values. Acta Materialia 50: 3717-3729

Lee D 1973 Science of hardness testing and its research applications. ASM International, 147-156

Ludwigson D G 1971 Modified stress-strain relation for fcc metals and alloys. Metallurgical Transactions 2: $2825-2828$

Marin J, Hu L W, Hamburg J F 1953 Plastic stress strain relations of Alcoa 14S-T6 for variable biaxial stress ratios. Trans. Am. Soc. Metals 45: 686-709

Mattiasson K, Sigvant M 2008 An evaluation of some recent yield criteria for industrial simulations of sheet forming processes. Int. J. Mech. Sci. 50: 774-787

Peters M, Eschweiler J, Welpmann K 1986 Strength profile in Al-Li plate material. Scripta Metallurgica 20: 259-264

Reed-Hill R E, Cribb W R, Monteiro S N 1973 Concerning the analysis of tensile stress-strain data using $\log \mathrm{d} \sigma / \mathrm{d} \varepsilon_{\mathrm{p}}$ versus $\log \sigma$ diagrams. Metallurgical Transactions 4: 2665-2667

Satyanarayana D V V, Malakondaiah G, Sarma D S 2004 Analysis of flow behaviour of an aluminium containing austenitic steel. Mater. Sci. Eng. 452-453: 244-253

Satyanarayana D V V, Satya Prasad K, Malakondaiah G, Sarma D S 2007 Strain hardening behaviour of an Fe-Ni-Cr-Al alloy. Mater. Sci. Technol. 23: 79-86

Siegert K, Wagner S 1994 Formability characteristics of aluminum sheet. Lecture notes on training in aluminum application technologies, EAA- European Aluminum Association

Sivaprasad P V, Venugopal S, Venkadesan S 1997 Work hardening behaviour of the Ni-Fe based superalloy IN718. Metallurgica Materials Trans. A 28: 171-178

Storen S, Rice J R 1975 Localized necking in thin sheets. J. Mech. Phys. Solids 23: 421-441

Stoughton T B 2000 A general forming limit criterion for sheet metal forming. Int. J. Mech. Sci. 42: 1-27

Stoughton T B 2001 Stress-based forming limits in sheet-metal forming. ASME J. Eng. Mater. Technol. 123: 417-422 
Stoughton T B, Yoon J W 2005 Sheet metal formability analysis for anisotropic materials under nonproportional loading. Int. J. Mech. Sci. 47: 1972-2002

Stoughton T B, Zhu X 2004 Review of theoretical models of the strain-based FLD and their relevance to the stress-based FLD. Int. J. Plasticity 20: 1463-1486

Tempus G, Calles W, Scharf G 1991 Influence of extrusion process parameters and texture on mechanical properties of Al-Li extrusions. Mater. Sci. Technol. 7: 937-945

Wheeler R G, Ireland D R 1966 Multiaxial plastic flow of zircoalloy - 2 determined from hardness data. Electrochem. Technol. 4: 313-317

Zhu X, Weinmann K, Chandra A 2001 A unified bifurcation analysis of sheet metal forming limits. J. Eng. Mater. Technol. 123: 329-333 